\title{
Overview of methods for overcoming hindrance to drug delivery to tumors, with special attention to tumor interstitial fluid
}

\author{
Gianfranco Baronzio ${ }^{1 *}$, Gurdev Parmar ${ }^{2}$ and Miriam Baronzio ${ }^{1}$ \\ ${ }^{1}$ Integrative Oncology Section, Medical Center Kines, Milan, Italy, ${ }^{2}$ Integrated Health Clinic, Fort Langley, BC, Canada
}

OPEN ACCESS

Edited by:

Juan José Lasarte,

Centro de Investigación Médica

Aplicada, Spain

Reviewed by:

Raquel Aloyz,

Lady Davis Institute for Medical

Research, Canada

Heiko Rieger,

Saarland University, Germany

*Correspondence:

Gianfranco Baronzio,

Department of Integrative Oncology,

Kines Medical Center, Via San

Gerolamo 29, Castano Primo,

Milan 20022, Italy

barongf@intercom.it

Specialty section:

This article was submitted to Molecular and Cellular Oncology, a section of the journal

Frontiers in Oncology

Received: 17 April 2015

Accepted: 06 July 2015

Published: 23 July 2015

Citation:

Baronzio G, Parmar G and

Baronzio M (2015) Overview of

methods for overcoming hindrance to

drug delivery to tumors, with special

attention to tumor interstitial fluid.

Front. Oncol. 5:165.

doi: 10.3389/fonc.2015.00165
Every drug used to treat cancer (chemotherapeutics, immunological, monoclonal antibodies, nanoparticles, radionuclides) must reach the targeted cells through the tumor environment at adequate concentrations, in order to exert their cell-killing effects. For any of these agents to reach the goal cells, they must overcome a number of impediments created by the tumor microenvironment (TME), beginning with tumor interstitial fluid pressure (TIFP), and a multifactorial increase in composition of the extracellular matrix (ECM). A primary modifier of TME is hypoxia, which increases the production of growth factors, such as vascular endothelial growth factor and platelet-derived growth factor. These growth factors released by both tumor cells and bone marrow recruited myeloid cells form abnormal vasculature characterized by vessels that are tortuous and more permeable. Increased leakiness combined with increased inflammatory byproducts accumulates fluid within the tumor mass (tumor interstitial fluid), ultimately creating an increased pressure (TIFP). Fibroblasts are also up-regulated by the TME, and deposit fibers that further augment the density of the ECM, thus, further worsening the TIFP. Increased TIFP with the ECM are the major obstacles to adequate drug delivery. By decreasing TIFP and ECM density, we can expect an associated rise in drug concentration within the tumor itself. In this overview, we will describe all the methods (drugs, nutraceuticals, and physical methods of treatment) able to lower TIFP and to modify ECM used for increasing drug concentration within the tumor tissue.

Keywords: tumor interstitial fluid, tumor interstitial fluid pressure, drug delivery systems, chemotherapy, adjuvant, vascular normalization

\section{Introduction}

To produce its effects, a drug should reach the target tissue in a uniform and selective way. Although this effect has not been accomplished for any disease, with any drug currently used, this is true more than ever for tumors. Chemotherapy alone has not proven its effectiveness and efficacy; in fact, studies over 5 years have produced a paltry percentage of $2.1 \%$ (1).

Although several criticisms can be moved to this article, it is the only one that has produced reliable data on a large population and has shown which tumors may benefit from the use of chemotherapy. The work does not analyze the reasons for this failure. In fact, it was not possible to analyze 
the mode of drug administration, the various cocktails used, and if they were properly prepared. Furthermore, it was not easy to study all the anatomical parameters (currently known by in vitro and animal studies) that were able to decrease the arrival of the drugs to the tumor. The first studies that have taken into account the reasons why chemotherapeutics are not able to achieve their antitumor effect are to ascribe to Jain et al. (2). These authors studied the pharmacokinetics of methotrexate (MTX) in two transplanted-animal carcinoma: Walker 256carcinoma (W256) and hepatoma 5123 (H5123). A difference was present in the two tumors regarding the distribution of MTX. The uptake of drugs by $\mathrm{H} 5123$ was conditioned by the plasmatic concentration, whereas, in the W256, the tissue barriers conditioned it. It is interesting to report the methods used by these authors. The authors (2) studied the pharmacokinetics of MTX in W256 and H5123 by transplanting the tumors in three different ways. The first method of transplantation was the standard implantation of tumor frustules in the subcutaneous tissue. The second method was the implantation of a Millipore chamber inside the tumor mass for sampling tumor interstitial fluid (TIF) (3). The third method used tumor implantation to obtain a tumor supply by the host connecting it to a single artery and vein $(4,5)$. The single artery and vein connection is a superb method for studying tumor blood perfusion and vasoactive drug effects, metabolites, and drug characterization (6). To determine experimentally the release of drugs into tumors, Jain and coworkers (7-10) used several methods of study. One method was the isolated organ of Gullino, as previously reported. The other methods were the preparations of microcirculatory units. One method was the "Window technique" (7), and the other was a new angiogenesis assay $(9,10)$. This new assay was able to quantify angiogenesis, red blood cell velocity, microvascular permeability, $\mathrm{pH}$, and growth factors $(9,10)$. From these early pharmacokinetic studies and the combined use of these experimental methods, Jain concluded that the drugs do not come easily to the tumor mass (7). Jain also stressed that different barriers prevent their arrival and that increased interstitial pressure is the main impediment (11). Other researchers have confirmed the existence of these anatomical and physiological barriers $(12,13)$. As recently pointed out by Monsky (12), barriers related to the anatomy and physiology of the tumor are the tumor vasculature, the interstitial space, and the same tumor cells.

Associated with increased interstitial pressure, the irregular vasculature is responsible for the decreased intake of drugs (11, $12,14,15)$.

\section{Tumor Vasculature Interstitial Fluid Formation, Increase of Interstitial Fluid Pressure}

As long as the tumor in its growth does not exceed a distance from the nourishing vessels $>1-2 \mathrm{~mm}^{3}$, the tumor remains well oxygenated and nourished. Once this volume is exceeded, many cells become hypoxic and undernourished (15). At this point, a mechanism common to many hypoxic situations is triggered that seeks to bring nourishment and oxygen to these suffering cells $(15,16)$. The defense mechanism triggered by a transcription factor called hypoxia-inducible factor (HIF), regulate the production of several growth factors and trigger angiogenesis (17). Among growth factors, vascular endothelial growth factor A (VEGF-A) and platelet-derived growth factor (PDGF) are the most studied (18-22). VEGF and PDGF not only exert mitogenic effects on endothelial cells $(21,23$, 24) but also sustain inflammatory reactions. In fact, VEGF and PDGF recruit myeloid and immature cells from the blood marrow. These cells contribute to building the new vasculature (25-28).

As reported by Narang (14), the excessive quantity of vascular cytokines and growth factors in the tumor microenvironment (TME) determines an irregular growth of vessels compared to its normal counterparts. In conclusion, the tumor vasculature is a defective vasculature compared to that appearing during wound repair or in normal tissues $(19,23)$. In fact, tumor vasculature appears with a non-ordered 3D branching, lacking smooth muscles, and pericytes, with a scarce or missing innervation with irregular basement membrane $(14,27)$. The architecture of the tumor vasculature is aberrant (27) and develops in similar way in many types of tumors $(29,30)$. Furthermore, Azzi and Nagy $(31,32)$ describe a loss of cellular junctions integrity. This loss of integrity is responsible for the increased permeability of the tumor neovessels $(31,32)$. Another factor contributing to increasing the permeability of tumor vasculature is the excessive production of VEGF. In fact, a study by Roberts and Palade (33) has demonstrated that VEGF increases the permeability of postcapillary venules, increasing their fenestration. This fenestration effect was also present in the endothelium not usually fenestrated, such as skin and muscle. Weis and Cheresh (34) reported a similar increase in permeability and edema in cancer and in ischemic tissues. These structural effects are the result of biochemical defects induced by VEGF (35). The simultaneous presence of increased permeability, lack of lymphatic drainage $(36,37)$, and chronic inflammation in the TME carries to an accumulation of fluid in the interstitium $(38,39)$. The chronic inflammatory reaction is elicited by VEGF (40) and other cytokines/chemokines present in the TME $(41,42)$. Various authors demonstrated the increased interstitial fluid accumulation $(3,38,43-45)$. To understanding better this fluid accumulation, a digression on the forces that govern the exchange of liquids in capillaries is useful. Ernest Starling (46) formulated the various factors that regulate the filtration of liquids through the vascular wall and the exchange of fluids between interstitium and plasma in 1896. It is because two major gradient forces present at the level of the capillaries control this transfer the hydrostatic pressure that favors the filtration, and the osmotic pressure gradient, that favors resorption. Mathematically, is expressed as:

$$
\mathrm{Jv}=(\operatorname{LpS})[(\mathrm{Pc}-\mathrm{Pi})-\sigma(\pi \mathrm{c}-\pi \mathrm{i})]
$$

where Jv is the volume flux of fluid ( $\mathrm{ml} / \mathrm{min})$; Lp is hydraulic conductivity $\left(\mathrm{cm} \mathrm{min}^{-1} \mathrm{mmHg}^{-1}\right)$; $\mathrm{s}$ is the capillary surface area $\left(\mathrm{cm}^{2}\right)$; Pc and Pi are capillary and interstitial fluid hydrostatic pressures, respectively $(\mathrm{mmHg}) ; \pi \mathrm{c}$ and $\pi \mathrm{i}$ are capillary and 
interstitial colloid (oncotic) pressures, respectively ( $\mathrm{mmHg}$ ); and $\sigma$ is the osmotic reflection coefficient of the vessel wall ( $\sigma 0$ if the membrane is fully permeable to transport molecular species and $\sigma 1$ if the membrane is impermeable) $(38,46-47)$. This equation still cannot fully explain the formation of interstitial fluid in pathological situations to complete it, it is necessary to introduce a new parameter that is the flow of liquid removed from the interstitium by the lymphatic system. The equation is modified taking into account the amount of liquid removed by the lymphatics: JL $(38,46,47,48)$ :

$$
\mathrm{Jv}=(\mathrm{Lp} S)[(\mathrm{Pc}-\mathrm{Pi})-\sigma(\pi \mathrm{c}-\pi \mathrm{i})]-\mathrm{JL}
$$

In tumor mass, however, these forces are not regulated for various reasons such as capillary tumor pressure The change in hydrostatic pressure along the length of the capillary tumor is lower than that of the normal capillary (MVP). This pressure decrease gives rise, as described by some authors, to a stagnant tumor blood flow (49). Furthermore, the tumor blood viscosity is increased, and this aggravates further the perfusion (50). A second factor is related to the osmotic pressure, slightly elevated in the tumor interstitium, compared to plasma. Another important factor is the composition of the interstitial fluid itself, richer in collagen and glycosaminoglycans that acts almost like a sponge sucking up the interstitial fluid. The last, but probably the most important, factor is that the tumor inside its mass lacks a functioning lymphatic system $(36,37)$.

The net result of this non-equilibrium is an accumulation of the liquid (TIF) in a confined space, determining an increase in the tumor interstitial fluid pressure (TIFP). The volume occupied by TIF varies between 30 and $60 \%$ of tumor water, depending on tumor type, as reported by Gullino (43-45). In addition, other components of TIF vary according to the tumor type studied and to the methodologies used. For example, a difference exists in the protein content using Gullino technique (capsule method) (43) and the method of Sylven and Bois that obtained TIF by micropipettes (51). The same applies to the components of the matrix. For example, glycosaminoglycans have a higher concentration in the TIF compared to normal interstitium $(11,52)$. Recently, some authors have begun to study the interstitial fluid of patients with cancer proteomics method, in order to obtain new tumor biomarkers $(38,39$, $53,54)$. Another important aspect is to describe the pressure exerted by the TIF and the consequent interstitial fluid flow (IFF) generated (39). The TIFP following Guyton $(55,56)$ is physiologically the result of two components: the pressure exerted by the cellular component and that of the gel phase. In the tumor, the tissue pressure (or solid pressure) is made up of growing tumor cells, fibroblasts, and the extracellular matrix (ECM). The gel phase is constituted of the filtrate of tumor vessels in the TIF $(57,58)$. Before Guyton, average interstitial fluid pressure (IFP) was thought to be near zero or positive, after the use of capsule method it has been found to be near zero or sub-atmospheric $(55,56)$. Young was the first to measure TIFP and was followed by Gullino and Jain $(3,11,59)$. These authors demonstrated in animal and human studies that TIFP is greater than in normal tissue and positive, reaching in particular tumors the value of $100 \mathrm{mmHg}$ (i.e., Melanoma) (range 10-40 $\mathrm{mmHg}$ ) (60-62). As outlined by Jain, TIFP decreases from the center of the tumor toward the periphery and correlated to volume (60). IFF is the fluid present in the stroma and is poorly drained by lymphatics and maintained by the TIFP gradient (63-65). In fact, as reported by Jain (63), IFF is proportional to the pressure gradient, and its velocity hampers the convective movement of drugs. The velocity of the IFF that affects hydraulic conductivity $(\mathrm{K})\left[\mathrm{cm}^{2} / \mathrm{mmHg} / \mathrm{s}\right]$ is proportional to the pressure gradient. Its velocity value in tumor tissue ranges from 0.59 to $55 \mu \mathrm{m} / \mathrm{s}$, which is a higher value compared to normal tissue $(0.1-1 \mu \mathrm{m} / \mathrm{s})$ (64-66). Butler et al. (64) were the first to study the existence of IFF through the micropore chamber method implanted in murine mammary tumors. These authors affirmed that IFF was comparable to lymphatic drainage and takes importance in drug concentration and distribution (64). Several methods have been used to study IIF. Chary and Jain studied the diffusion of albumin in rabbit ear chamber of normal and neoplastic tissue analyzing the fluorescence recovery after photobleaching. These authors founded that the average IFF velocity was about $0.6 \mu \mathrm{m} / \mathrm{s}$ and directed toward the postcapillary venules (67). Munson et al. analyzed the mean velocity found in vivo in different cancer types and report a median velocity of 0.5 to $55 \mu \mathrm{m} / \mathrm{s}$ for non-metastatic tumors and values between 10 and 55 for metastatic tumors (65). Other authors followed the development and the flux of IFF by magnetic resonance imaging (MRI) $(66,68)$. The IFF velocity is dependent on the structure and composition of the extracellular compartment and the physicochemical properties of the drug or solute used (63). The IFF increase, as demonstrated in vivo using xeno-engrafted models of various types of human tumors, has its maximum at the periphery of the tumor and its minimum within the tumor mass (66). As outlined by Yao, the content of the interstitium (Collagen fibrils association) and the vascular architecture are the major modifiers of the IFF (69). Other researchers show that IFF is involved with various factors that may enhance tumor progression. In fact, IFF participates in lymphatic dissemination $(66,70)$ and has an immunomodulatory effect $(71)$. Rutokowski et al. have experimentally demonstrated that IFF increases angiogenesis and lymphangiogenesis. In fact, IFF also acts as a morphoregulator (72) increasing endothelial sprouting, adhesion, permeability, and produces migratory activity in fibroblasts. Furthermore, IFF induces secretion of cytokines and metalloproteinases by these tumor associated fibroblasts (MMPs) $(73,74)$ (TIF formation is summarized in Box $\mathbf{1}$ ).

BOX 1 | TIF formation is the result of three important factors simultaneously present in the tumor area.

They are (a) an unbalanced Starling mechanism acting in tumor microcirculation, (b) increased vascular permeability, due to an abnormal tumor vasculature, (c) a malfunctioned lymphatic system inside the tumor mass. Both these factors generate an increased interstitial pressure (TIFP) and interstitial fluid flow (IFF), moving from the tumor into the near microenvironment. IFF with TIFP hinders drug distribution $(11,38,39,63,72,211)$. 


\section{Forces that Govern Drug Distribution from Vascular Wall to Cancer Cells}

The drugs must be divided into drugs with a size $\leq 1 \mathrm{~nm}$ and superior to $\geq 1 \mathrm{~nm}$. In Table 1, following Multhoff and Vaupel (75), we report the list of drugs with their size. The first obstacle to overcome is the vascular wall (see Figure 1). Transvascular wall mass transport may be diffusive or convective, dependent on osmotic and pressure exiting on the two sides of the vascular wall. Mass transport happens through pores present in the capillary wall. As previous reported tumor vasculature is peculiarly leaky due to an increased number of fenestrae created by VEGF. Disputes regarding the dominant channels that permit the passage of different molecules occurred [see Ref. (76)]. According to Sarin (77), the physiologic upper limit of vascular pore size ranges between 5 and $12 \mathrm{~nm}$. A study by Monsky with the intention of measuring changes in permeability and pore cutoff under increasing dosages of VEGF has demonstrated that it is possible to increase pore size in the range that permits the passage of molecules with ranges between 100 and $300 \mathrm{~nm}$ (78). Once the drug has crossed the vascular wall, it must reach the cancer cells traveling along the interstitium. At this point, the interstitial transport of the drug is again dependent on the size. If the size is $\leq 1 \mathrm{~nm}$ (as are the majority of normal chemotherapeutics), travel is governed by diffusion parameters (Fick's law). Fick's law is mathematically formulated $(11,79)$ as:

$$
\mathrm{JD}=-(\partial \mathrm{C} / \partial \mathrm{x})
$$

where JD is the diffusive flow of the solute $\left(\mathrm{g} / \mathrm{s} \times \mathrm{m}^{2}\right)$ and $\mathrm{D}$ is the diffusion of the solute in the medium $\left(\mathrm{m}^{2} / \mathrm{s}\right)$. Even if the molecular size of the molecules are $\leq 1 \mathrm{~nm}$, they encounter several difficulties in penetrating into tumor mass. These impediments are as follows: (a) the increased distance between the vessel wall and the cancer cells due to the increased volume of tumor interstitium; (b) the diffusion coefficient of tumors; and (c) the presence of a centrifuge flow (IFF) from the tumor center toward the periphery, governed by the IFP. Diffusion coefficient measures are not easy, and Jain (11) describes the methods. The author outlines that D is dependent on many factors, such as water content, molecular weight of the solute, temperature, configuration, and charge and binding of the solute with matrix components. Molecules, such as

TABLE 1 | Drugs and particles dimension according to the organization for standardization.

\begin{tabular}{lc}
\hline Type of nanoparticles & Size (nm) \\
\hline Gold nanoparticles & 2.5 \\
Monoclonal antibodies & $10-15$ \\
Oncolytic viruses & $30-40$ \\
Magnetic nanoparticles & $15-100$ \\
Liposome encapsulated doxorubicin & $80-130$ \\
Gadolinium-based nanoparticles & 115 \\
Albumin-paclitaxel nanoparticles & 130 \\
\hline
\end{tabular}

Modified from Multhoff and Vaupel (75)*.

*http://wwwiso.org/iso/home/search.htm?qt=nanoparticles\&sort=rel\&type= simple\&published $=$ on nanoparticles or monoclonal antibodies, are transported into the interstitium to cancer cells by convective flow that is formulated following Pusenjak and Miklavcic (79) and Jain (11) as

$$
\mathrm{JC}=-\mathrm{C} \times \mathrm{RF} \times \mathrm{K} \times(\partial \mathrm{p} / \partial \mathrm{x})
$$

where JC is the convective flow of solute $\left(\mathrm{g} / \mathrm{s} \times \mathrm{m}^{2}\right)$; C is the concentration of solute $\left(\mathrm{g} / \mathrm{m}^{3}\right)$; RF is the retardation factor (solute convective velocity/solvent convective velocity); $\mathrm{K}$ is the hydraulic conductivity $\left(\mathrm{m}^{2} / \mathrm{P} \cdot \mathrm{a} \times \mathrm{s}\right)$; and $\partial \mathrm{p} / \partial \mathrm{x}$ is the hydraulic pressure gradient. Hydraulic conductivity $\mathrm{K}$ and the retardation factor seem dependent on the quantity of polysaccharides and the quantity of water present in the interstitium $(11,79,80)$. RF is a parameter dependent on the solute (structure, content in water, and molecular properties) (81).

Another important factor that prevents the arrival of drugs over the interstitial pressure increase but is dependent on it is IFF. Recently, to overcome the complexity of exiting through tumor vascularization, permeability, lymphatics, IFF, and drug transport, Welter et al. have developed a computational model (82). This model predicts interesting behaviors of TIFP and IFF on drug transport in the presence of a heterogeneous tumor vasculature. The authors conclude that IFF is more responsible than TIFP in obstructing drug penetration (82) (Box 2). This effect is, of course, according to this model more at the tumor periphery where IFFs' velocity is greater. This last effect is in agreement with the observations of Butler et al. $(11,64)$ that describe that TIF oozes out a quantity of four to five times greater than that in subcutaneous tissue. The model of Welter also predicts that reducing tumor leakiness is not as effective as tumor normalization. Increased tumor permeability may increase drug delivery toward the tumor center where TIFP is greater but IFF velocity is less (82). Other authors using another numerical modeling demonstrated that the irregularities of tumor vasculature influences greatly IFF flux and TIFP (83-85).

\section{Techniques for Measuring Tumor Interstitial Fluid Pressure}

Tumor interstitial fluid can be measured with different techniques that may be divided according to Wiig $(86,87)$ into acute or chronic, and into invasive and not invasive.

\section{Acute Invasive Methods}

The invasive methods can be used in an acute way, such as the technique of Wick catheter, or in a chronic way, as with the implanted perforated capsules (86). Hargens (88) subsequently amended the Wick technique developed by Scholander (89). It consists of a needle filled with a saline solution and its ends a suture thread of dacron. This catheter is then inserted into another catheter (that acts as a guide) and positioned in the skin. The Wick catheter connected to a transducer to record the variation in pressure displaces the guide catheter. A variation of this method is that developed by the group of Aukland called the WIN technique (90). Another acute way is the glass micropipettes used by Wiederhielm in the late 1970 (91). The means of adopting the needles to measure the IFP are, according to Guyton, 


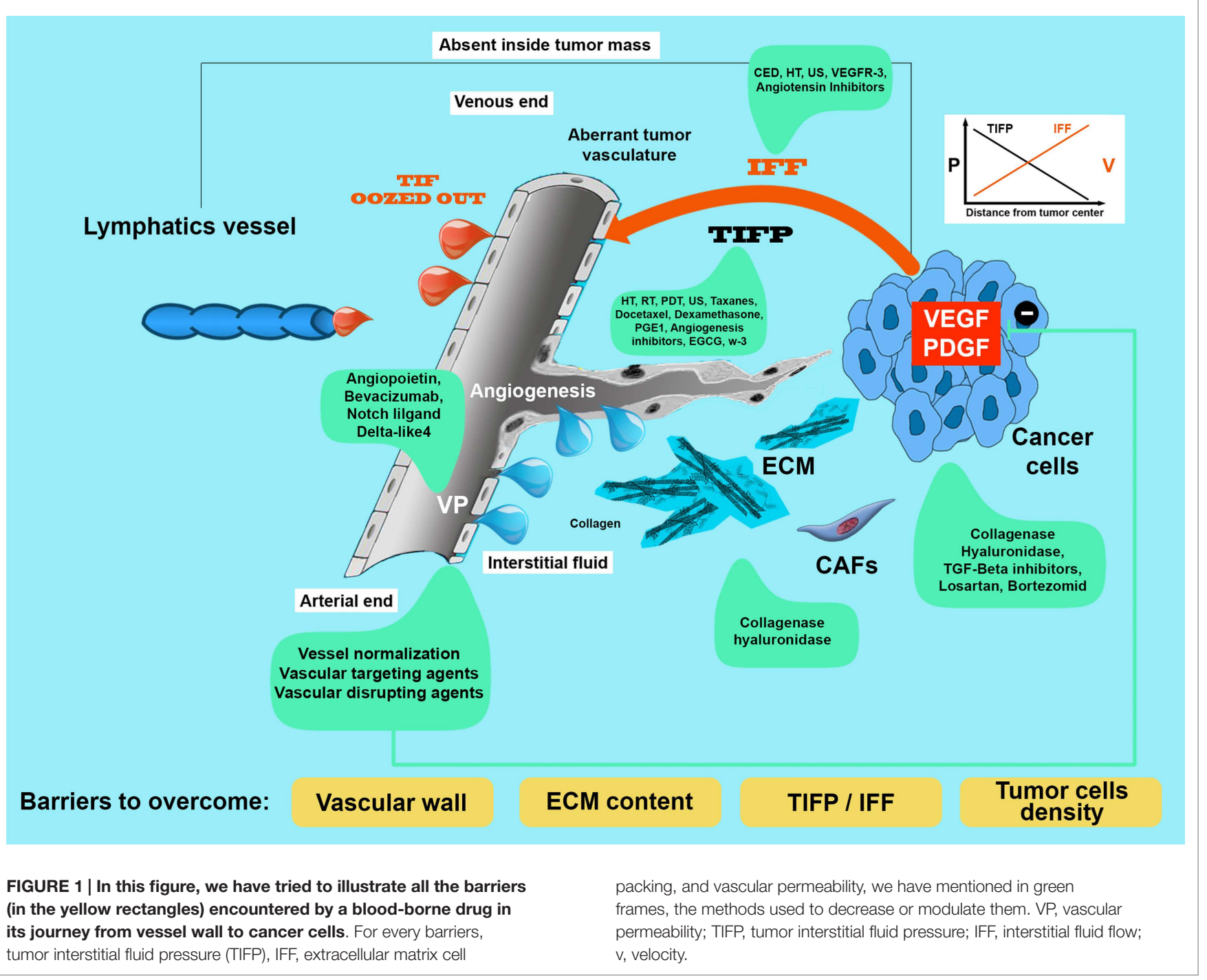

BOX 2 | Drugs (apart their molecular weight and physical properties) $(11,200)$ distribute inside tumor mass under the pressures of two principal forces: the TIF and the IFF.

IFF is generated by TIF pressure difference $(82,200)$. Furthermore, matrix composition plays an important role in hampering drug penetration (212).

not adequate (55). In fact, the diameter of these needles is often considerably higher, up to 500 times than the interstitial space to measure. We refer the reader to the review of Wiig $(86,87)$ for a complete list of methods of measurement of interstitial fluid and the critical aspects of these applications. A summary on the advantages disadvantages and clinical utility of these methods is formulated in Table 2 (Box 3) (92-94).

\section{Chronic Methods}

The chronic methods of measurement of IFP are obtained by subcutaneously inserting capsules of polyethylene. They differ in the number of holes on their surface and in the diameter. The pressure measurement is, in one case, done by inserting a catheter inside the capsule, while the other type is directly in contact with the interstitial fluid. The measurement is carried out by connecting the catheter to a pressure transducer (86).

Not all the methods briefly described so far are applicable to humans, except the method of Wick used to measure the TIFP of superficial melanoma or lymphoma nodules (95). Recently, a method to determine TIFP non-invasively has been attempted, unsuccessfully correlating the TIFP with the proton relaxation rate of the magnetic resonance (96). From this failure, Hassid and his group showed that using the proton relaxation time of gadolinium makes it possible to determine the IFP and its spatial distribution $(97,98)$. Gade and his group, using MRI, have gone further and found that it is possible to quantify the uptake of 5-fluorouracil (5-FU) using a collagenase for degrading the ECM collagen (99). Despite the usefulness and versatility of magnetic resonance, its applicability to the patient is not immediate. As suggested by Hassid, we must take into account gadolinium's side effects (fibrosis) to the kidneys (98). 
TABLE 2 | Methods for measuring interstitial pressure (IP) in tumors.

\begin{tabular}{|c|c|c|c|c|c|}
\hline Type & Method & Tip diameter & Advantage & Disadvantage & Clinical utility \\
\hline A & Needle & $0.5 \mu \mathrm{m}$ & Simplicity & Tissue destruction and trauma & For superficial visible tumors \\
\hline$A^{*}$ & $\begin{array}{l}\text { Win } \\
\text { (Wick-in-needle) }\end{array}$ & 23G needle & $\begin{array}{l}\text { Versatile, recorded pressure similar to } \\
\text { micropipette }\end{array}$ & Tissue destruction and trauma & $\begin{array}{l}\text { For superficial tumors (i.e., } \\
\text { melanoma, breast) }\end{array}$ \\
\hline A & Micropipette & $2-5 \mu \mathrm{m}$ & Reduced tissue destruction and trauma & $\begin{array}{l}\text { Not possible to measure IP at depth } \\
\geq 800 \mu \mathrm{m} \text { fragility, immobilization of tissue }\end{array}$ & $\begin{array}{l}\text { Only for superficial visible } \\
\text { tumors. Extremely delicate }\end{array}$ \\
\hline C & $\begin{array}{l}\text { Micropore } \\
\text { Chamber }\end{array}$ & D C $0.8-3 \mathrm{~cm}$ & $\begin{array}{l}\text { Useful for following biochemical and } \\
\text { physiological parameters }\end{array}$ & $\begin{array}{l}\text { Animal preparation not simple peculiarly } \\
\text { vascular pedicle - not sensitive to TIFP } \\
\text { acute change }\end{array}$ & No, but sometimes used \\
\hline NIM & MRN & & $\begin{array}{l}\text { Useful for following various } \\
\text { microenvironmental parameters(i.e., oxygen } \\
\text { content, tumor vascularity, tumor perfusion) }\end{array}$ & $\begin{array}{l}\text { Construction of special image platform } \\
\text { analysis, possible severe side effects to } \\
\text { kidneys }\end{array}$ & $\begin{array}{l}\text { Yes: expensive dedicated } \\
\text { structure and staff }\end{array}$ \\
\hline
\end{tabular}

A, acute method; C, chronic method; DC, diameter of the capsule; MRN, magnetic resonance imaging; NI, non-invasive methods; $A^{*}$, standard method according to Wiig.

\section{BOX 3 | In Table 2, the two groups of methods are compared.}

The advantages and disadvantages briefly analyzed. In every case, the notation of Pusenjak and Miklavcic (79) is correct. Any method of measurement is imperfect but can be used, provided it is reproducible and easy to use. In the specific case of the TIFP, the wick-in-needle technique seems the most used and reproducible, at least in animal studies and in some superficial human tumors (melanoma, breast, cervix, and head and neck tumors) $(61,79)$. MRI for humans will be the most applicable method even if expensive.

Another technique able to monitor non-invasively the pharmacokinetics of a drug is positron emission tomography (PET). An example of PETs use is the pharmacokinetics study in vivo of carbon-11 labeled docetaxel $\left(\left[(11)^{\mathrm{C}}\right]\right.$ docetaxel). Van der Veldt studied this labeled drug in lung patients (100). They studied the biodistribution of the drug and the tumor uptake. It is interesting to note that some patients were treated before $\left(\left[(11)^{\mathrm{C}}\right]\right.$ docetaxel) with dexamethasone. A difference between the two groups in drug uptake has been recorded in favor of the patients pretreated with dexamethasone (100).

\section{Strategies for Modulating Interstitial Fluid Pressure and Other Factors that Obstacle Cancer Therapy}

From these considerations, we can deduce that several factors may limit the delivery of the drugs to the tumor (see Figure 1) (Box 2). The first one is the increased distance that a drug must cross due to the volume increase. The second is the interstitial pressure (TIFP) that apparently produces a current flow from inside to outside of the tumor mass (60). This flow from the inside toward the outside slows the transportation of the drug from inside the vessel toward the tumor mass. TIFP is not only an obstacle to conventional therapy (chemotherapy) (101) but also hinders monoclonal antibodies $(102,103)$, nanoparticles (104, 105), and radionuclides delivery (106).

The pressure exerted by TIF is the result of two components the liquid component (gel phase) and the solid phase (cancer cells plus ECM) (107). Similar to liquid phase, the pressure of the solid phase is greater within the tumor mass than outside. Solid phase can collapse the blood vessel and is responsible for the lack of nourishment (and drugs) in particular areas of the tumor mass. Before listing and showing the studies conducted to decrease these two components (see Table 3), it is necessary to mention two studies that clearly illustrate that the modification of the interstitial pressure is indeed associated with a therapeutic improvement. The experimental study was conducted by Salnikov et al. (108). The authors examined two experimental tumors: syngenic rat colonic carcinoma (PROb) and dimethylbenza-anthracene-induced rat mammary carcinoma (DMBA) treated with prostaglandin of E1 type (PGE1) and radiolabeled 5 -FU $[3 \mathrm{H}] 5-\mathrm{FU}$. The authors clearly demonstrated that PGE1 exerted a substantial reduction of TIFP increasing the delivery of 5-FU, and the effect was not dependent on immune response or changes in tumor vascularity. The other study was conducted by Curti et al. (95) on nodules of patients with melanoma and lymphoma. Interstitial pressure was measured using the wickin-needle technique. The sizes of the nodules were studied with ultrasound (US), and tumors were followed over time. Tumors were treated with either chemotherapy regimens rather than with immunotherapy. Responsiveness was correlated with IFP. In Table 3, all the methods (drugs, natural substances, and physical methods of treatment) used to modify TIF are illustrated. We have, also tried to show the human and animal studies, and to distinguish between the IFP exerted by the gel and solid phase and the possible clinical relevance.

\section{The Concept of Tumor Vascular Normalization}

Jain (111) introduced the concept of normalization of tumor vasculature. Jain and colleagues noted that using angiogenesis inhibitors an increase in oxygenation and drug delivery associated with a decrease in interstitial pressure. They also noted that an improvement in the release of nanoparticles with diameters $\leq 12 \mathrm{~nm}$, disfavoring those with diameters $>125 \mathrm{~nm}$ (112). The authors point out, however, that the effect of normalization is dose and time dependent (113). In fact, studies that employed high doses of bevacizumab showed that not only the tumor growth was slowed but also the coverage of vessels by pericytes was increased, thus decreasing the arrival of monoclonal antibodies to the tumor $(114,115)$. Huang $(113)$ also emphasized the possibility of using the inhibition of angiogenesis as an immunomodulator as the 
TABLE 3 | Drugs, physical methods of cure, and natural drugs used to decrease tumor interstitial fluid pressure (TIFP), IFF, and VP.

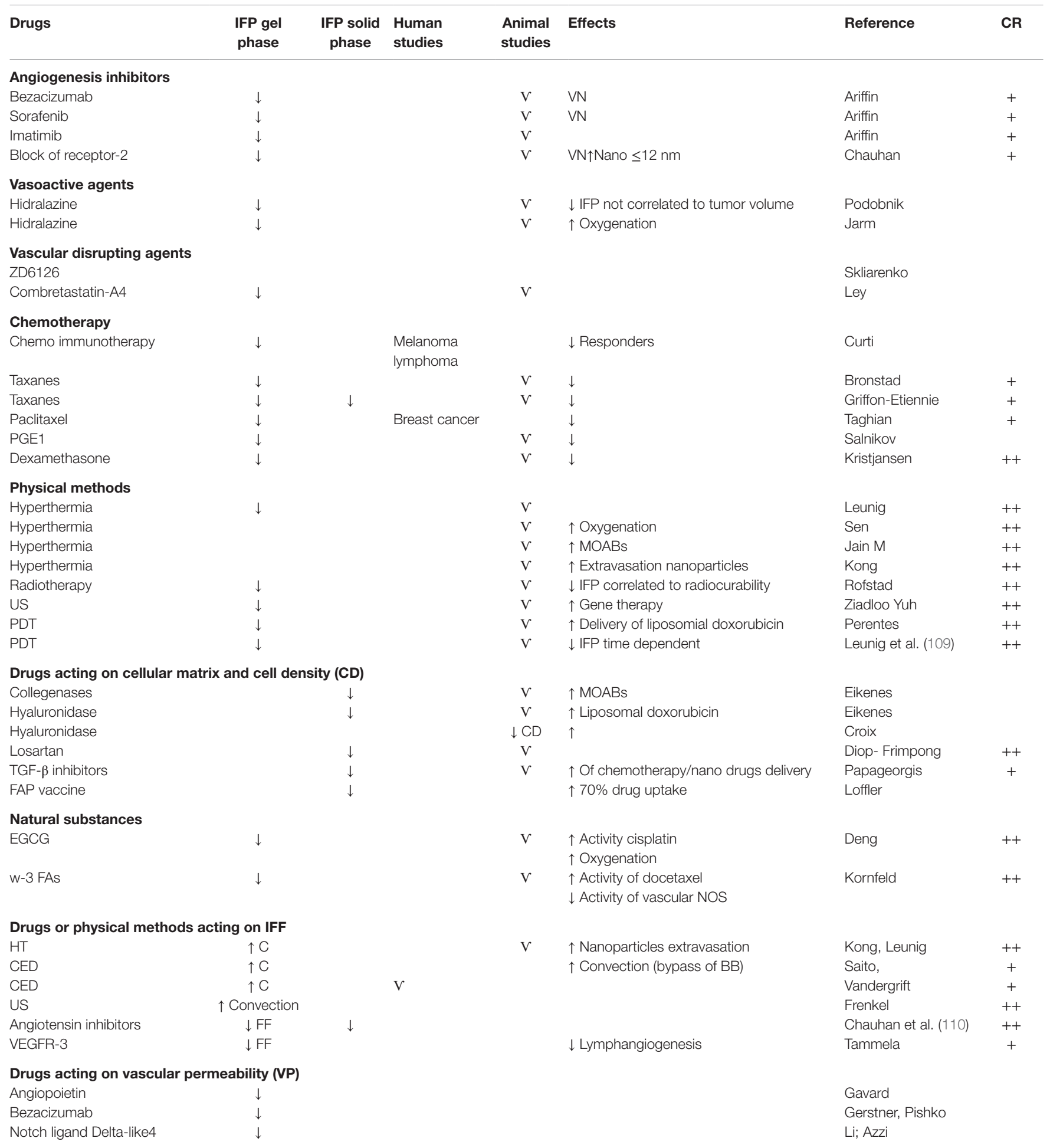

BB, blood brain barrier; IFP, interstitial fluid pressure; IFF, interstitial fluid flow; EGCG, epigallocathechin-3-gallate; W-3FAs, omega-3 fatty acids; VN, vascular normalization; $C L$, capillary leakage; $\downarrow$, decrease; $\uparrow$, increase; $\uparrow C$, increased convection; $C D$, cell density; $C E D$, convection enhanced delivery; $C R$, clinical relevance, + with certain side effects, ++ with scarce side effects; NOS, nitric oxide synthase; MOABs, monoclonal antibodies.

abnormal vascularization that generates hypoxia also generates an immunosuppressive and inflamed TME (116). In addition to increased drug efficacy, Shrimali et al. (117) showed in a mouse model of melanoma that inhibition of angiogenesis increases lymphocytic infiltration and the effectiveness of adoptive cell therapy. In addition to immunotherapy, some chemotherapeutics, 
such as carboplatin and paclitaxel, enhance their effectiveness in the presence of an anti-angiogenic therapy. Heist et al. showed that associating anti-VEGF with chemotherapy improved the survival and the free period of illness in patients with advanced non-small lung cancer. It was also shown that it is possible to follow these patients with appropriate marks. For example, a high value of placental-derived growth (PIG) factor is associated with treatment with VEGF, and a high value of the receptor 1 of VEGF (VEGFR1) before treatment with bevacizumab with chemotherapy is a negative prognostic index (118).

\section{Vascular Disrupting Agents}

Vascular disrupting agent (VDA) is a new class of drugs that affect the preexisting vasculature in the tumor mass (119). They mainly act by disrupting the integrity of the endothelial cytoskeleton inducing apoptosis and necrosis. As outlined by Ariffin (57), necrosis is able to increase hydraulic conductivity by indirectly decreasing TIFP. Two studies seem particularly interesting that confirm the effect of VDA on the interstitial pressure. The first is an experimental study on two tumors transplanted in mice, murine fibrosarcoma tumors (KHT-C) and a line of human cervical cancer (CaSki). These two tumors were treated with a binding agent, tubulin ZD6126, and interstitial pressure was measured using the wick-in-needle method (120). The TIFP behaved differently in the two types of tumor. The KHT-C tumors showed a sudden drop in TIFP $1 \mathrm{~h}$ after treatment, with a gradual slope and lifts to pre-treatment values about $3 \mathrm{~h}$ later. A drop of $25 \%$ of the pre-treatment values occurred after $72 \mathrm{~h}$. The TIFP in the CaSki tumors decreased gradually over time, instead, reaching a value of $-30 \%$ after $72 \mathrm{~h}$. The mice with the two types of transplanted tumors showed a significant increase in survival after treatment (120). The second study was conducted on $\mathrm{C} 3 \mathrm{H}$ mammary tumors grown subcutaneously in the foot of female CDF1 mice. The mice were treated with a single intraperitoneal injection of CA4DP. Tumor perfusion was recorded using a Laser Doppler flowmetry, and TIFP was measured continuously using the wick-in-needle technique (121). TIFP decreased rapidly after the treatment, followed by a concomitant reduction in tumor perfusion. According to the authors, perfusion increase was not TIFP dependent.

\section{Vasodilators}

Several drugs with vasodilator activity have been shown in experimental studies to be able to decrease the interstitial pressure (122). In any case, a premise is necessary because the behavior of these drugs is not unique. Tumor vessels are devoid of innervation and part of tumor vasculature is that of the host, that is innervated and responsive to pharmacological stimuli. As pointed out by Vaupel (123), the effect produced by vasodilators depends on the positioning of the vessels of the host with those neo-formed. In fact, if the circulation of the tumor and that of the host are in parallel, the effect of the vasoactive drug is a decrease of flow in tumor; if the movement is in series, the vasoactive drugs produce an increase of flow into the tumor mass (123). Studies by Podobnik on SAF and LPB tumors have reported a decrease of TIFP in the presence of hydralazine. The decrease in interstitial pressure was not correlated with tumor volume (124). Studies by Jarm et al. have confirmed the positive association between hydralazine and TIFP but have also reported a decrease in tumor oxygenation (125). This last effect is probably due to steal phenomena and to the observations made by Vaupel (123).

\section{Chemotherapy}

The low-molecular weight drugs used in chemotherapy reach the tumor by diffusion through the capillaries toward the tumor mass. Drugs with a higher molecular weight (i.e., monoclonal antibodies, nanoparticles, immune system cells) reach the tumor mass by convention (see Table 2). The most studied class of chemotherapeutics was the taxanes (paclitaxel and docetaxel) $(126,127)$. The Bronstad group has studied how taxane influence the ECM composition, specifically B1 integrins. They noted that the inhibitory effect on TIFP is linked to the action on the integrin, that both paclitaxel and docetaxel decrease TIFP in a dose-dependent manner, and that the fixing of actin filaments by phalloidin abolishes the effect of paclitaxel. The group of Griffon-Etienne has studied the effects of the taxanes on TIFP of two experimental tumors: the murine mammary carcinoma (MCa-IV) and the human sarcoma HSTS-26T. They determined that the taxane was able to decrease both the cell density (solid phase) and the gel phase. Taghian et al. studied the effects of paclitaxel on patients known to suffer from breast cancer (128). These authors noted that the decrease in interstitial pressure was followed by an improvement in oxygenation and that the effect was independent of tumor volume. Furthermore, the authors noted that only the paclitaxel seemed to achieve this effect. In fact, the concomitant administration of doxorubicin did not show any effect on TIFP and oxygenation.

Dexamethasone is a synthetic glucocorticoid used before or concomitantly with chemotherapy to reduce side effects (129) or increase the antitumor activity of certain drugs, such as carboplatin and gemcitabine (130). In addition to these activities, dexamethasone has been shown to decrease interstitial pressure. This activity study was conducted in SCID mice transplanted with tumor line LS174T. Two weeks after transplantation, mice were treated daily with intraperitoneal dexamethasone. A significant reduction in TIFP due to a reduced microvascular permeability and vascular hydraulic conductivity was obtained compared to a control group (131).

\section{Physical Methods Hyperthermia}

Hyperthermia (HT) is a method of treating tumors using heat (132). Leunig et al. treated with HT several Amelanotic melanoma (A-Mel-3) implanted into the dorsal skin of Syrian golden hamsters. They studied the effect of HT on TIFP by using the wick-in-needle technique (133). They noted that the reduction of TIFP was temperature and time dependent, and the biological response was correlated with the TIFP reduction. Recently, Sen et al. (134) demonstrated similar results in several murine models. In addition, the authors noted that the reduction of TIFP was associated with an increase in perfusion and a sustained reduction of hypoxia. This reduction of hypoxia has led to a considerable improvement when radiotherapy was administered $24 \mathrm{~h}$ after HT. 


\section{Radiotherapy}

Radiation therapy with chemotherapy is the standard therapies commonly used to treat solid tumors. Human melanoma xenografts transplanted intradermally or in window chamber preparations in $\mathrm{BALB} / \mathrm{c} \mathrm{nu} / \mathrm{nu}$ mice were studied and treated with radiotherapy according their TIFP value. Mice with higher TIFP were treated with a higher radiation dose compared to those with a lower IFP. This indicates that a strong relationship exists between TIFP and radiocurability (135). The work of Rofstad et al. has associated the radiocurability to the value of the interstitial pressure, not taking into account that the radiotherapy is able to decrease the TIFP. Znati et al. (136) have highlighted this fact, and showed in xenografts of LS174T human colon adenocarcinoma grown in the right flank of nude (BALB/c) mice, that TIFP and tumor oxygenation were lowered by radiotherapy (RT). This effect was dose dependent, and it was necessary to give a dose between 10 and 15 Gy at minimum. The TIFP decrease and oxygen increase were dose dependent but not volume dependent. Anyway, Multhoff and Vaupel have doubts about the consistency of the data when applied to humans. They argue that the effects of radiation therapy on microcirculation as that on TIFP and drug delivery need more experimental data (75).

\section{Photodynamic Therapy}

Photodynamic therapy (PDT) is a minimally invasive method that uses a photosensitizer, the visible light of appropriate length and oxygen to generate oxygen free radicals (ROS). The ROS generated determine tumor cell death by apoptosis, disrupt the tumor vasculature, and generate a local inflammation and antitumor immunity $(137,138)$. Another positive effect of PDT is the capacity to lower TIFP. The first observations of this phenomenon were made by Leunig et al. in 1994 (109). These authors studied the time course of TIFP in nodules of melanoma implanted subcutaneously in four different districts of Syrian golden hamsters. They noted that the TIFP behaved differently depending on the time in which it was measured after the application of PDT. In fact, the TIFP exhibited an increase from 40 to $60 \%$ in the first $6 \mathrm{~h}$, probably due to the impairment implemented on tumor microcirculation. After $<24 \mathrm{~h}$, the TIFP subsided by $50 \%$ compared to the control. A more recent study conducted on metastases of sarcoma in rats with subpleural implantations showed attractive valuations in Fisher rats (139). The PDT was able to decrease the TIFP in tumor nodules but not in the lung, and this was associated with a greater distribution of epirubicin in the tumor mass. In summary, the decrease of TIFP was associated with an increased convection of the drugs compared to controls.

\section{Ultrasound Therapy}

The US technique for depositing medication in the interstitial space is an emerging and promising method. In summary, drugs are activated via US and then released accurately and with decreased toxicity by using an imaging guide (140). Watson's group (141) intended to study a method for reducing epithelialmesenchymal transition (EMT), a situation with a propensity to metastasize and develop resistance to chemotherapy (142). In fact, these cells lose their polarity and adhesion capacity acquiring the capacity to migrate (143). In order to investigate the differences between epithelial tumors and tumors with EMT characteristics, liposomes containing radiolabeled $64 \mathrm{Cu}$ can be used.

This allows the labeled liposomes to be followed by PET. Liposomes were found to accumulate in greater amounts (1.5fold increase) in epithelial tumors compared to tumors with EMT characteristics without US application, whereas following US application; liposomes accumulated more in EMT compared to epithelial tumors. According to the authors (141), the nanoparticle accumulation was the result of TIFP reduction and of the increase in vascular permeability.

\section{Drugs Acting on Cellular Matrix}

The arrival of new pharmaceutical formulations, such as liposomes or nanoparticles with a diameter $>10 \mathrm{~nm}$, has highlighted the contribution of the composition of tumor matrix to drug delivery $(144,145)$. The deposition of the ECM is a complex process that involves two main components: cellular components (fibroblasts and inflammatory cells) and non-cellular components (146). In the presence of tumor cells, fibroblasts acquire special features to become the cancer-associated fibroblasts (CAFs). The stimulated CAFs produce the components of the matrix (147).

The main groups of components are glycoproteins, proteoglycans, and collagen. Each component has its physiological function, for example, seizure of growth factors, or provision of substrates to allow certain biochemical reactions or tissue differentiation (146, 148-150). A dynamic interaction exists between cancer cells, CAFs, and ECM, and their interaction is regulated by important cytokines, such as transforming growth factor- $\beta$ (TGF- $\beta$ ) and PDGF (146). TGF- $\beta$ stimulates CAFs to produce collagen type I, rendering the ECM stiffer and participating with VEGF to sustain angiogenesis and lymphangiogenesis (146).

The journey that a drug in the blood must take to reach the cancer cells in a body is similar to traveling through an obstacle course. Figure 1 shows all the obstacles that need to be overcome. In addition, the liquid part of the TIF drug should exceed cell densification and the composition of the ECM. Studies conducted by Netti have clearly demonstrated that the total content of collagen type I is more important than the content of glycosaminoglycans in halting the travel of the drugs (145). The author argues that less dense and less organized cellular matrix is capable of allowing a greater uptake of monoclonal and macromolecule cancer cells. Several authors aware of this factor tried to modulate the ECM. In order to obtain this, used enzymes were used to disrupt the ECM or the inhibitors of growth factors, such as PDGF and TGF- $\beta$, that control the formation of ECM $(144,151-155)$. Brekken et al. were among the first to demonstrate that injecting inside tumor enzymes, such as hyaluronidase or collagenase, which degrade the ECM was possible to modify the transvascular pressure (156). Eikenes demonstrated that collagenase (151) and hyaluronidase (152) were able to modulate the ECM and increase the monoclonal antibodies in the first case and lipoxomal doxorubicin in the second study. In both studies, the model studied was osteosarcoma xenografts, and the TIFP was measured by the wick-inneedle technique. Collagenase was injected peritoneally, whereas hyaluronidase was injected intratumorally and intravenously. 
The TIFP decrease behaved differently in the two groups. In the group treated with collagenase, the TIFP decreased as the microvascular pressure MVP, whereas in the group treated with hyaluronidase, the improved distribution of lipoxomal doxorubicin was induced by an increased transcapillary gradient. Diop-Frimpong et al. conducted an interesting work with an antihypertensive drug losartan (144). Losartan, an angiotensin II receptor antagonist, does not only exert antihypertensive activity but also has antifibrotic activity. This activity is carried out by reducing the activity of TGF- $\beta 1$. The synthesis of collagen I decreases after 2 weeks and is dose dependent. As reported by Diop-Frimpong (144), collagen I synthesis was reduced under losartan in several experimental tumors, with minimal side effects. The results of experiments indicate that there is an amelioration of nanotherapeutics [(gene therapy) herpex simplex viruses] and pegylated liposomal doxorubicin uptake by tumor. Another molecule that is able to decrease TIFP is PDGF inhibitors. It seems that PDGF is able to increase IFP in the dermis by interfering with integrins and phosphatidylinositol- $3^{\star}$ kinase signaling (157). Pietras et al. using A PDGF receptor tyrosine kinase inhibitor (STI571), increased the uptake of taxol in an experimental model of subcutaneous (s.c.) implanted KAT-4 tumors in SCID mice (154). Another group tested the same PDGF inhibitor (155) in a s.c. xenografts of human colorectal carcinoma in athymic mice treated with a radiolabeled antibody B72.3. They demonstrated an improvement of radioimmunotherapy uptake. The antibody uptake was more homogeneous and associated with an augmented radiosensitivity due to an increased oxygenation of the tumor mass. As previously described, TGF- $\beta$ is one of the principal cytokines that regulate the ECM and collagen deposition. This last effect is obtained by converting fibroblasts into CAFs and stimulating them to produce lysyl oxidase, an enzyme that is able to stiffen collagen (153, 158). The authors suggest the use of inhibitors of TGF- $\beta$ in tumors with strong desmoplasia because, in their view, it should result in increased perfusion. Emphasize, however, that the increase in perfusion would indirectly increase the capillary pressure (Pc, see Figure 1) with an increase of filtration. Increased filtration increases the interstitial fluid and then would form a vicious circle. Furthermore, the block of TGF- $\beta$ was also shown to increase metastasis. A combined treatment with chemotherapeutic type taxanes, losartan, and inhibitors of TGF- $\beta$ should optimize the result and not trigger the vicious circle (153). An example of this association is the work of Zhong (159). Furthermore, these authors using chemotherapeutic cyclophosphamide not only controlled the metastases but also enhanced antitumor immunity. Loeffler et al. have addressed the problem of the matrix and deposition of collagen type I, trying to regulate fibroblasts the fabricators of collagen. They used a DNA vaccine for the oral fibroblast activating protein (FAP), which is overexpressed in tumor stroma. With this method, they were able to decrease the production of collagen and increase by $70 \%$ the uptake of chemotherapy by the tumor cells (160). Bouzin et al. emphasize that a difference exist between collagenase and hyaluronidase (161). According to these authors, the degradation of fibrillar collagen is more efficient on drug uptake than the degradation of hyaluronan. Collagenase, as previous discussed, increases the uptake of monoclonal antibodies and the efficiency of herpes simplex virus (161).

\section{Natural Substances (Nutraceuticals)}

The use of nutraceuticals as adjuvant to traditional cancer therapy is increasing. Two substances have been studied regarding the possibility to lower the TIFP, which are the epigallocatechin3-gallate (EGCG) (162) and omega-3 fatty acids (163). EGCG is a molecule with an anti-angiogenic activity. In fact, EGCG has the capacity to regulate the receptor of VEGF and to modulate the angiopoietins 1 and 2 (Ang-1; Ang-2) (164). Ang-2 may loosen the endothelial cells' junctions rendering more leaky tumor vessels. EGCG inhibited both Ang-1 and Ang-2 but had a greater effect on Ang-2, thus, decreasing the tumor vessel's permeability and, in effect, TIFP level. Deng demonstrated this phenomenon in mice with xenografts in A549 cells. TIFP was measured using the wick-in-needle technique, and hypoxia was measured using polarographic needle electrodes. EGCG showed a synergism with cisplatin, indicating the possibilities of using EGCG to decrease TIFP and as a sensitizer to chemotherapy (162). Kornfeld used omega-3 fatty acids (w-3 FAs) to control TIFP. As known from the literature, omega-3 fatty acids (w-3) have multiple effects on cancer prevention and therapy (165). Among the most important effects were anti-angiogenic activity and the modification of nitric oxide synthase. Nitric oxide (NO) and VEGF are responsible for vascular hyperpermeability (163, 165). The inhibition or modulation of these two factors normalizes the abnormal vascular structure of tumors, as pointed out by Jain. Based on this, Kornfeld (163) studied a breast cancer model in mice. Kornfeld et al. subjected a group to a diet rich in w-3 polyunsaturated fatty acids (50\% DHA 20\% EPA), another group with this diet and docetaxel, and another group as the control. They then studied the synthesis of NO in vitro using a human umbilical vein. The group treated with w-3 + docetaxel showed vasculature normalization, decreased drug resistance, improved drug delivery, and a change in nitric oxide activity.

\section{Cell Packing, Density}

At the end, a drug must overcome another obstacle, the difficulty of penetrating and accumulating at the necessary concentration in the tumor cell mass. The difficulty level is higher for protein binding drugs, such as doxorubicin and paclitaxel (166). The factor that determines decreased penetration is cell density (167). The authors conclude that drug penetration in a $3 \mathrm{D}$ structure is 5- to 10 -fold less effective than in a monolayer. Tredan et al. outline further this concept and consider cell density one of the causes of tumor drug resistance associated with TME characteristics (i.e., hypoxia, extracellular acidity) (168). We can define TME (cell density) as a set of cancer cells, normal cells, tumor/ normal vascular structure, and ECM dense packed together. Furthermore, tumor cells can be distinguished between well oxygenated, hypoxic, and moderately oxygenated embedded in an ECM rich in cytokines and growth factors. As previously mentioned, ECM is denser than normal matrix and related to the deposition of collagen (145). This dense complex of tumor cells, normal cells, and ECM forms a special microenvironment that hinders further penetration of drugs, resulting in a situation of drug resistance $(150,168-171)$. These authors point out that the methods to study the tumor drugs must be ameliorated. Culture 
studies on monolayers should be replaced with studies with spheroids or with cultures on multilayers and in vivo methods (171). An example of these methodologies is the recent work of Grantab et al. (172). These authors used two variants of HCT-8 human colon carcinoma xenografted in nude mice and a multilayered cell culture. One of these variants had a lower packing density, and the other had greater density. They treated the two groups with bortezomid and showed improvement in drug penetration, an increased cytotoxicity, and a reduction in cell density. A decrease in TIFP was also noted. Another study by Croix demonstrated that hyaluronidase was able to reverse the cell density, increasing tumor cell sensitivity to various chemotherapeutics (173).

\section{Drugs Acting on IFF Drugs that Augment Convection Convection enhanced delivery}

With convection enhanced delivery (CED) we intend a treatment able to overcome the IFF current from the tumor toward the environment or the lymphatic vessels. This kind of therapy, normally, is used to treat glioblastoma overcoming the obstacle of the blood brain barrier (BBB) (174). The method consists of the insertion into the brain tissue of a small caliber catheter stereotactically guided toward the tumor mass. The first to describe this methodology was Bobo et al. (175) in late 1994. Debinsky et al. described the different kinds of catheters used for CED (176). Saito et al. (177) developed special liposomes labeled with gadolinium and a fluorescent indicator. They followed and monitored their distribution inside the brain tumors of rats after a microinfusion under pressure. The technique (CED) increased the local drug delivery and demonstrated its clinical use. The molecules (radioisotope labeled drugs, immunotoxins) were pumped through this catheter to penetrate the brain parenchyma. Vandergrift et al. (178) report the phase I, II, and III clinical trials conducted with CED technique. Phases I and II have been completed and have shown promising results consisting of partial response while avoiding side effects. Limitations of the techniques are linked to the tumor's location and are justified by the tumor's aggressiveness. The catheters generally must provide sufficient infusate and prevent reflux. The leakage of refluxed infusate is the most important side effects associated to the possibility of infections (179).

Other two methods can augment convection: HT and US. As previously reported, HT increases drugs' extravasation and accumulation into the tumor mass, also decreasing TIFP (133, 180). Another physical method that is able to increase convection is the use of US (181).

\section{Drugs that Decrease IFF}

Another way to increase the arrival of drugs to the tumor is to hinder or decrease the effect of the IFF by increasing the pressure in the vessels that supply the tumors. This result is achieved using antagonists against the angiotensin II receptors (110). Experimental studies have demonstrated that these antagonists can increase the perfusion of the tumor vessels by decreasing the IFF indirectly. Other positive effects are an enhancement of oxygen delivery to the tumor and a potentiation of chemotherapy, such as 5-FU in AK4.4 pancreatic tumors. The increased release of drugs has also been shown in pancreatic tumors, human breast, and skin cancers. What these tumors have in common is the high concentration of collagen in the ECM that the angiotensin inhibitors can reduce. As to chemotherapy, the authors demonstrated that the distribution of the nanoparticles, liposomal doxorubicin, and oncolytic virus also undergoes an improvement (144). Another way to decrease the efflux of IFF is to inhibit the transport by the lymphatic system. An example of this approach is the use of monoclonal antibodies that block VEGF receptor type 3 (182, 183). As demonstrated by Alitalo et al. (182), VEGF receptor type 3 is an essential signaling mechanism in lymphangiogenesis and tumor progression. The decreased drainage via the lymphatic system reduces the IFF and drug removal (65).

\section{Drugs Acting on Vascular Permeability}

The mechanisms that regulate the vascular endothelial permeability are essentially two: the tight junctions (TJ) and the adherent junctions (AJ). The TJ represent the barrier capable of regulating cell migration, while AJ maintain the physical junction between the endothelial cells. Among the various trans membrane proteins belonging to $\mathrm{AJ}$ the most important are the VE-cadherin proteins and anchor proteins $\alpha, \beta, v$, and p-120 catenins. The VE-cadherin bind to $\beta$-catenins and $\beta$ to $\alpha$-catenins forming a complex that interact with the proteins of the cytoskeleton. This complex interacts with regulatory proteins, such as Src kinase and several phosphatases that modulate the AJ junctions $(184,185)$. The restoration of vascular permeability is here briefly described as we invite the readers to see the review of Azzi et al. (184) for a more complete discussion of the argument.

\section{Angiopoietin}

Vascular endothelial growth factor is the principal enhancer of the endothelial permeability. It produces this effect acting on VE-cadherin through a mechanism Src dependent. The angiopoietin blocks the destabilization of VE-cadherin although collaborates on angiogenesis. The angiopoietin in conclusion has angiogenic activity as VEGF but otherwise has no activity on vascular permeability (186).

\section{Bevacizumab}

Vascular normalization as outlined by Jain (187) is a method able to carry for limited period to normality the abnormal tumor vasculature. For limited period, we intend the period during which anti-angiogenetic drugs exert their effect. Jain and his group demonstrated that normalization in glioblastoma is able to decrease hypoxia, to increase drug arrival and survival. Survival was associated to an increase in tumor perfusion (188). Gerstner and Batchelor reported similar results and outline that brain edema, which is the result of $\mathrm{BBB}$ disruption, was less using one of most known anti-angiogenetic monoclonals bezacizumab (189). Pishko et al. (190) using bezacizumab demonstrated vascular normalization in rat model of human cancer brain metastases.

\section{Notch Ligand Delta-Like 4}

Li et al. in the late 2007 (191) founded that beyond VEGF Notch ligand Delta-like 4 (DL4) plays a role in angiogenesis. DL4 is 
a negative regulator of angiogenesis reducing the quantity of neovessels. DL4 improves vascular function but does not interfere with the activity of bezacizumab and reduce both angiogenesis and the vascular effect (permeability) of VEGF (184).

\section{Conclusion}

The status of the TME should be of primary importance for oncologists (170). The possibility of studying it in vivo by MRI may contribute to their ability to choose the most appropriate drugs use (chemotherapy/natural drugs or monoclonal antibodies). These drugs are able to modify TME and, consequently, the tumor interstitium (192-197). In fact, MRI offers the possibility of knowing the density of the matrix, the forces that govern the distribution of drugs, the perfusion, the $\mathrm{pH}$ of the microenvironment, and its metabolic status $(195,196,198)$. As with conformal radiotherapy (CFRT), a computerized, imaging reconstruction platform can be used and analyzed by a staff composed of physicists, biologists, and physicians. In the near future, it will be possible to comprehend the TME of any patient and apply a personalized treatment (196). As to the CFRT, it is clear that semiautomatic image analysis methods will provide a better understanding of angiogenesis and modulation of interstitial pressure $(98,199)$. There is no doubt that mathematical and silicon models will be helpful in this process, transitioning experimental studies from the laboratory to the clinic $(82,200)$. As reported by Kuszyk (199), the barriers that obstruct drug delivery: (a) the vascular transport, (b) the crossing of vessel walls, and (c) the distribution inside the interstitium can be studied by MRI.

We have considered, in this review, drugs that can interfere with interstitial pressure. In Table 3, we have introduced the concept of clinical relevance $(+)$. By this, we mean drugs or methods currently used and able to achieve a higher deposition of drugs. Some methods that we stressed $(++)$ seem more usable, with fewer side effects. It is interesting to note that some nutraceuticals have activities on TIFP, which partially explains their activities in sensitizing tumor cells to chemotherapy. Many new studies that take into account these nutraceuticals would be useful and desirable. However, we must avoid an incorrect association that would decrease some pharmacological activities. Another consideration is that cancer patients often have other associated disorders, such as diabetes or heart disease (201). In the case of diabetes, it would be interesting to see if some medications, such as metformin, can be used for reducing collagen synthesis, fibrosis (202), or angiogenesis (203). In this review, the dynamic process of angiogenesis has not described except in summary form. Neoangiogenesis is definitely the most important phenomenon in the genesis of the increased interstitial pressure and in tumor progression (61). In fact, the growth, irregular and imperfect of the new endothelium, is responsible for the increased permeability (27) and for the lack of oxygenation of some tumor areas and the perpetuation of the phenomenon: angiogenesis, hypoxia, and angiogenesis (204). The abnormal and unregulated growth of 3D tumors linked to irregular spraying leads to the inadequate distribution of medications and, consequently, a resistance to them. The opportunity to use more drugs (natural or synthetic) can lead to a normalization of tumor blood circulation and to important effects, such as an increased release of drugs and an increased immune response (187). The improvement of the imaging methods will permit to test clinically new therapies in a quicker time. This method will enable us shortly to use the best therapies for individuals (precision medicine) knowing the status of the patient's TME.

An interesting and useful method that is an example of ongoing research between experimental measurements and possible future applications at the bedside is the study of Leguerney et al. (205). These authors performed the measurement of tumor volume, perfusion, and TIFP on 60 mice xenografted with B16F10. They treated the animals with an association of sorafenib and bezacizumab. The two drugs as reported by the authors to have a positive association with a variety of tumors. Perfusion and vasculature were measured by quantitative dynamic contrastenhanced ultrasonography (DCE-US), whereas TIFP measured with a fiberoptic probes. The authors demonstrated that TIFP variations were predictive of vascular changes and that a single measure of TIFP was sufficient for characterizing the entire tumor mass. Authors refer that no correlation present between TIFP value and tumor perfusion. This method is interesting for the following reasons. DCE-US is relatively inexpensive and used at the patient bed permitting to follow the application of anti-angiogenic drugs. Disadvantages are probably the difficultness to measure the parameters in deep-seated tumors and the invasive way of TIFP measure. Another disadvantage is that the technique is not applicable to all the patients and probably not easy reproducible.

A phenomenon that we have not analyzed but correlated to the increased permeability of tumor vessel is the so-called retention enhancement effect (EPR) of Maeda. This phenomenon regards drugs with a molecular weight $\geq 12,000 \mathrm{Da}$, nanoparticles and liposomes (206). As outlined by Jang et al. EPR is a passive tumor targeting approach (207). The EPR effect is another example of interaction between TIFP and IFF. As discussed, TIFP is a uniformly centripetal pressure, whereas IFF has a centrifugal behavior. However, TIFP is sufficiently elevated compared to the pressure difference existing between the tumor vessels and the normal tissue around a tumor. This in a certain sense hampers the transport away of the molecules adjacent to the vessel area, keeping them in that area for a longer time (EPR effect) (82).

Vascular normalization seems to be the simplest method of treatment for controlling TIF formation and TIFP. However, Ribatti (208) has criticized vascular normalization. In fact, this author outlines that the vessel normalization's restoration followed by normalization of vessel permeability may become an obstacle to the subsequent chemotherapy (208). This is true, but we think that a better comprehension of TIF formation, TME, and of the forces that govern their interactions, associated with vascular normalization and the new imaging methods and computational models, may represent the future of cancer therapy. Another way to lowering TIFP and ameliorating convective flux is the use of collagenase. The work of Gade et al. (99) is the one of the best example to transport into clinics. In fact, the authors followed with MRI the increase in delivery of 5-FU to HT29 human colorectal tumors grown s.c. in mice after administration of collagenase. They demonstrated a 50\% increase in 5-FU increase 
in mice treated with collagenase compared to a control (99). HT clinically if properly used is free of serious side effects. HT associated with chemotherapy and radiotherapy increases their antitumoral effects. We refer the reader to Datta et al. (209) and Hurwitz et al. (210) to understand the mechanisms that determine these positive associations. We can point out that the right combination of them (i.e., cisplatinum-taxanes-HT-radiotherapy)

\section{References}

1. Morgan G, Ward R, Barton M. The contribution of cytotoxic chemotherapy to 5-year survival in adult malignancies. Clin Oncol (R Coll Radiol) (2004) 16(8):549-60. doi:10.1016/j.clon.2004.06.007

2. Jain RK, Wei J, Gullino PM. Pharmacokinetics of methotrexate in solid tumors. J Pharmacokinet Biopharm (1979) 7(2):181-94. doi:10.1007/ BF01059737

3. Gullino PM, Clark SH, Grantham FH. The interstitial fluid of solid tumors. Cancer Res (1964) 24:780-94.

4. Grantham FH, Hill DM, Gullino PM. Primary mammary tumors connected to the host by a single artery and vein. J Natl Cancer Inst (1973) 50(5):1381-3.

5. Duyverman AM, Kohno M, Roberge S, Fukumura D, Duda DG, Jain RK. An isolated tumor perfusion model in mice. Nat Protoc (2012) 7(4):749-55. doi:10.1038/nprot.2012.030

6. Tozer GM, Shaffi KM, Prise VE, Cunningham VJ. Characterisation of tumour blood flow using a 'tissue-isolated' preparation. Br J Cancer (1994) 70(6):1040-6. doi:10.1038/bjc.1994.445

7. Jain RK. Barriers to drug delivery in solid tumors. Sci Am (1994) 271(1):58-65. doi:10.1038/scientificamerican0794-58

8. Jain RK. Delivery of molecular and cellular medicine to solid tumors. Adv Drug Deliv Rev (2012) 64(Suppl):353-65. doi:10.1016/j.addr.2012.09.011

9. Dellian M, Witwer BP, Salehi HA, Yuan F, Jain RK. Quantitation and physiological characterization of angiogenic vessels in mice: effect of basic fibroblast growth factor, vascular endothelial growth factor/vascular permeability factor, and host microenvironment. Am J Pathol (1996) 149(1):59-71.

10. Dellian M, Helmlinger G, Yuan F, Jain RK. Fluorescence ratio imaging of interstitial $\mathrm{pH}$ in solid tumours: effect of glucose on spatial and temporal gradients. Br J Cancer (1996) 74(8):1206-15. doi:10.1038/bjc.1996.518

11. Jain RK. Transport of molecules in the tumor interstitium: a review. Cancer Res (1987) 47(12):3039-51.

12. Monsky WL. Circumventing anatomic and physiologic barriers to the intratumoral delivery of therapeutics. Anat Physiol (2012) 2:2-4. doi:10.4172/ 2161-0940.1000e114

13. Sriraman SK, Aryasomayajula B, Torchilin VP. Barriers to drug delivery in solid tumors. Tissue Barriers (2014) 2:e29528. doi:10.4161/tisb.29528

14. Narang AS, Varia S. Role of tumor vascular architecture in drug delivery. $A d v$ Drug Deliv Rev (2011) 63(8):640-58. doi:10.1016/j.addr.2011.04.002

15. Vaupel P, Mayer A. Hypoxia in tumors: pathogenesis-related classification, characterization of hypoxia subtypes, and associated biological and clinicalimplications. Adv Exp Med Biol (2014) 812:19-24. doi:10.1007/978-1-49390620-8_3

16. Ramakrishnan S, Anand V, Roy S. Vascular endothelial growth factor signaling in hypoxia and inflammation. J Neuroimmune Pharmacol (2014) 9(2):142-60. doi:10.1007/s11481-014-9531-7

17. Hirota K, Semenza GL. Regulation of angiogenesis by hypoxia-inducible factor 1. Crit Rev Oncol Hematol (2006) 59(1):15-26. doi:10.1016/j. critrevonc.2005.12.003

18. TieJ,DesaiJ. Antiangiogenictherapiestargeting thevascularendotheliagrowth factor signaling system. Crit Rev Oncog (2012) 17(1):51-67. doi:10.1615/ CritRevOncog.v17.i1.50

19. Shibuya M. Vascular endothelial growth factor and its receptor system: physiological functions in angiogenesis and pathological roles in various diseases. J Biochem (2013) 153(1):13-9. doi:10.1093/jb/mvs136

20. Claesson-Welsh L, Welsh M. VEGFA and tumour angiogenesis. J Intern Med (2013) 273(2):114-27. doi:10.1111/joim.12019 can only lead to a better therapeutic index. In fact, if we look at all these various factors individually they lower the interstitial pressure augmenting drug delivery to the tumor. The experimental group directed by Repasky (134) comforts us. They are indicating that an appropriate use of oncology therapies and imaging methods already in use can cause us to take a big leap forward in the clinic.

21. Hicklin DJ, Ellis LM. Role of the vascular endothelial growth factor pathway in tumor growth and angiogenesis. J Clin Oncol (2005) 23(5):1011-27. doi:10.1200/JCO.2005.06.081

22. Battegay EJ, Rupp J, Iruela-Arispe L, Sage EH, Pech M. PDGF-BB modulates endothelial proliferation and angiogenesis in vitro via PDGF beta-receptors. J Cell Biol (1994) 125(4):917-28. doi:10.1083/jcb.125.4.917

23. Johnson KE, Wilgus TA. Vascular endothelial growth factor and angiogenesis in the regulation of cutaneous wound repair. Adv Wound Care (New Rochelle) (2014) 3(10):647-61. doi:10.1089/wound.2013.0517

24. Chung AS, Ferrara N. Developmental and pathological angiogenesis. Annu Rev Cell Dev Biol (2011) 27:563-84. doi:10.1146/annurev-cellbio-092910154002

25. Riabov V, Gudima A, Wang N, Mickley A, Orekhov A, Kzhyshkowska J. Role of tumor associated macrophages in tumor angiogenesis and lymphangiogenesis. Front Physiol (2014) 5:75. doi:10.3389/fphys.2014.00075

26. Furuya M, Yonemitsu Y, Aoki IIII. Angiogenesis: complexity of tumor vasculature and microenvironment. Curr Pharm Des (2009) 15(16):1854-67. doi:10.2174/138161209788453275

27. Munn LL. Aberrant vascular architecture in tumors and its importance in drug-based therapies. Drug Discov Today (2003) 8(9):396-403. doi:10.1016/ S1359-6446(03)02686-2

28. Nagaraja S, Wallqvist A, Reifman J, Mitrophanov AY. Computational approach to characterize causative factors and molecular indicators of chronic wound inflammation. J Immunol (2014) 192(4):1824-34. doi:10.4049/ jimmunol.1302481

29. Konerding MA, Fait E, Gaumann A. 3D microvascular architecture of pre-cancerous lesions and invasive carcinomas of the colon. Br J Cancer (2001) 84(10):1354-62. doi:10.1054/bjoc.2001.1809

30. Ackermann M, Konerding MA. Vascular casting for the study of vascular morphogenesis. Methods Mol Biol (2015) 1214:49-66. doi:10.1007/978-1-4939$1462-3 \_5$

31. Azzi S, Gavard J. [Blood vessels in cancer: can’t stop whispering]. Med Sci (Paris) (2014) 30(4):408-14. doi:10.1051/medsci/20143004015

32. Nagy JA, Dvorak AM, Dvorak HF. Vascular hyperpermeability, angiogenesis, and stroma generation. Cold Spring Harb Perspect Med (2012) 2(2):a006544. doi:10.1101/cshperspect.a006544

33. Roberts WG, Palade GE. Increased microvascular permeability and endothelial fenestration induced by vascular endothelial growth factor. J Cell Sci (1995) 108(Pt 6):2369-79.

34. Weis SM, Cheresh DA. Pathophysiological consequences of VEGF-induced vascular permeability. Nature (2005) 437(7058):497-504. doi:10.1038/ nature 03987

35. Bates DO. Vascular endothelial growth factors and vascular permeability. Cardiovasc Res (2010) 87(2):262-71. doi:10.1093/cvr/cvq105

36. Padera TP, Kadambi A, di Tomaso E, Carreira CM, Brown EB, Boucher Y, et al. Lymphatic metastasis in the absence of functional intratumor lymphatics. Science (2002) 296(5574):1883-6. doi:10.1126/science.1071420

37. Jain RK, Fenton BT. Intratumoral lymphatic vessels: a case of mistaken identity or malfunction? J Natl Cancer Inst (2002) 94(6):417-21. doi:10.1093/ jnci/94.6.417

38. Wiig H, Swartz MA. Interstitial fluid and lymph formation and transport: physiological regulation and roles in inflammation and cancer. Physiol Rev (2012) 92(3):1005-60. doi:10.1152/physrev.00037.2011

39. Wagner $\mathrm{M}$, Wiig $\mathrm{H}$. Tumor interstitial fluid formation, characterization, and clinical implications. Front Oncol (2015) 5:115. doi:10.3389/fonc.2015. 00115 
40. Angelo LS, Kurzrock R. Vascular endothelial growth factor and its relationship to inflammatory mediators. Clin Cancer Res (2007) 13(10):2825-30. doi:10.1158/1078-0432.CCR-06-2416

41. Landskron G, De la Fuente M, Thuwajit P, Thuwajit C, Hermoso MA. Chronic inflammation and cytokines in the tumor microenvironment. J Immunol Res (2014) 2014:149185. doi:10.1155/2014/149185

42. OnoM.Molecularlinksbetweentumorangiogenesisandinflammation:inflammatory stimuli of macrophages and cancer cells as targets for therapeutic strategy. Cancer Sci (2008) 99(8):1501-6. doi:10.1111/j.1349-7006.2008.00853.x

43. Gullino PM, Grantham FH, Smith SH. The interstitial water space of tumors. Cancer Res (1965) 25:727-31.

44. Gullino PM. The internal milieu of tumors. Prog Exp Tumor Res (1966) 8:1-25. doi:10.1159/000386002

45. Gullino PM. Extracellular compartments of solid tumors. In: Becker FF, editor. Cancer a Comprehensive Treatise. New York, NY: Plenum Press (1975). p. $327-54$.

46. Levick JR, Michel CC. Microvascular fluid exchange and the revised Starling principle. Cardiovasc Res (2010) 87(2):198-210. doi:10.1093/cvr/cvq062

47. Baronzio G, Schwartz L, Kiselevsky M, Guais A, Sanders E, Milanesi G, et al. Tumor interstitial fluid as modulator of cancer inflammation,thrombosis, immunity and angiogenesis. Anticancer Res (2012) 32(2):405-14.

48. Aukland K, Reed RK. Interstitial-lymphatic mechanisms in the control of extracellular fluid volume. Physiol Rev (1993) 73(1):1-78.

49. Jain RK. Delivery of molecular and cellular medicine to solid tumors. J Control Release (1998) 53(1-3):49-67. doi:10.1016/S0168-3659(97)00237-X

50. Jain RK. Determinants of tumor blood flow: a review. Cancer Res (1988) 48 (10):2641-58.

51. Sylven B, Bois I. Protein content and enzymatic assays of interstitial fluid from some normal tissues and transplanted mouse tumors. Cancer Res (1960) 20:831-6.

52. Gullino PM, Grantham FH, Clark SH. The collagen content of transplanted tumors. Cancer Res (1962) 22:1031-7.

53. Gromov P, Gromova I, Olsen CJ, Timmermans-Wielenga V, Talman ML, Serizawa RR, et al. Tumor interstitial fluid - a treasure trove of cancer biomarkers. Biochim Biophys Acta (2013) 1834(11):2259-70. doi:10.1016/j. bbapap.2013.01.013

54. Haslene-Hox H, Tenstad O, Wiig H. Interstitial fluid-a reflection of the tumor cell microenvironment and secretome. Biochim Biophys Acta (2013) 1834(11):2336-46. doi:10.1016/j.bbapap.2013.01.028

55. Guyton AC. Pressure-volume relationships in the interstitial spaces. Invest Ophthalmol (1965) 4(6):1075-84.

56. Guyton AC, Granger HJ, Taylor AE. Interstitial fluid pressure. Physiol Rev (1971) 51(3):527-63.

57. Ariffin AB, Forde PF, Jahangeer S, Soden DM, Hinchion J. Releasing pressure in tumors: what do we know so far and where do we go from here? A review. Cancer Res (2014) 74(10):2655-62. doi:10.1158/0008-5472.CAN-13-3696

58. Stapleton S, Milosevic MF. Pressure gradients in solid tumors. In: Bae YH, Mrsny RJ, Park K, editors. Cancer Target Drug Delivery. Springer (2013). p. 241-72.

59. Young JS, Lumsden CE, Stalker AL. The significance of the tissue pressure of normal testicular and of neoplastic (Brown-Pearce carcinoma) tissue in the rabbit. J Pathol Bacteriol (1950) 62(3):313-33. doi:10.1002/path.1700620303

60. Jain RK. Physiological resistance to the treatment of solid tumors. In: Teicher BA, editor. Drug Resistance in Oncology. Marcel Dekker (1993). p. 87-105.

61. Lunt SJ, Fyles A, Hill RP, Milosevic M. Interstitial fluid pressure in tumors:therapeutic barrier and biomarker of angiogenesis. Future Oncol (2008) 4(6):793-802. doi:10.2217/14796694.4.6.793

62. Milosevic M, Fyles A, Hedley D, Hill R. The human tumor microenvironment:invasive (needle) measurement of oxygen and interstitial fluid pressure. Semin Radiat Oncol (2004) 14(3):249-58. doi:10.1016/j. semradonc.2004.04.006

63. Jain RK, Chauhan VP, Duda DG. Vascular and interstitial biology of tumors. Abeloff Clinical Oncology Textbook (2014). p. 108-26.

64. Butler TP, Grantham FH, Gullino PM. Bulk transfer of fluid in the interstitial compartment of mammary tumors. Cancer Res (1975) 35(11 Pt 1):3084-8.

65. Munson JM, Shieh AC. Interstitial fluid flow in cancer: implications for disease progression and treatment. Cancer Manag Res (2014) 6:317-28. doi:10.2147/CMAR.S65444
66. Hompland T, Ellingsen C, Øvrebø KM, Rofstad EK. Interstitial fluid pressure and associated lymph node metastasis revealed in tumors by dynamic contrast-enhanced MRI. Cancer Res (2012) 72(19):4899-908. doi:10.1158/00085472.CAN-12-0903

67. Chary SR, Jain RK. Direct measurement of interstitial convection and diffusion of albumin in normal and neoplastic tissues by fluorescence photobleaching. Proc Natl Acad Sci U S A (1989) 86(14):5385-9. doi:10.1073/ pnas.86.14.5385

68. Pathak AP, Artemov D, Ward BD, Jackson DG, Neeman M, Bhujwalla ZM. Characterizing extravascular fluid transport of macromolecules in the tumor interstitium by magnetic resonance imaging. Cancer Res (2005) 65(4):1425-32. doi:10.1158/0008-5472.CAN-04-3682

69. Yao W, Shen Z, Ding G. Simulation of interstitial fluid flow in ligaments: comparison among Stokes, Brinkman and Darcy models. Int J Biol Sci (2013) 9(10):1050-6. doi:10.7150/ijbs.7242

70. Rofstad EK, Galappathi K, Mathiesen BS. Tumor interstitial fluid pressure-a link between tumor hypoxia, microvascular density, and lymph node metastasis. Neoplasia (2014) 16(7):586-94. doi:10.1016/j.neo.2014.07.003

71. Swartz MA. Immunomodulatory roles of lymphatic vessels in cancer progression. Cancer Immunol Res (2014) 2(8):701-7. doi:10.1158/2326-6066. CIR-14-0115

72. Rutkowski JM, Swartz MA. A driving force for change: interstitial flow as a morphoregulator. Trends Cell Biol (2007) 17(1):44-50. doi:10.1016/j. tcb.2006.11.007

73. Ng CP, Hinz B, Swartz MA. Interstitial fluid flow induces myofibroblast differentiation and collagen alignment in vitro. J Cell Sci (2005) 118(Pt20):4731-9. doi: $10.1242 /$ jcs. 02605

74. Shields JD, Fleury ME, Yong C, Tomei AA, Randolph GJ, Swartz MA. Autologous chemotaxis as a mechanism of tumor cell homing to lymphatics via interstitial flow and autocrine CCR7 signaling. Cancer Cell (2007) 11(6):526-38. doi:10.1016/j.ccr.2007.04.020

75. Multhoff G, Vaupel P. Radiation-induced changes in microcirculation and interstitial fluid pressure affecting the delivery of macromolecules and nanotherapeutics to tumors. Front Oncol (2012) 2:165. doi:10.3389/ fonc.2012.00165

76. Yuan F. Transvascular drug delivery in solid tumors. Semin Radiat Oncol (1998) 8(3):164-75. doi:10.1016/S1053-4296(98)80042-8

77. Sarin H. Physiologic upper limits of pore size of different blood capillary types and another perspective on the dual pore theory of microvascular permeability. J Angiogenes Res (2010) 2:14. doi:10.1186/2040-2384-2-14

78. Monsky WL, Fukumura D, Gohongi T, Ancukiewcz M, Weich HA, Torchilin VP, et al. Augmentation of transvascular transport of macromolecules and nanoparticles in tumors using vascular endothelial growth factor. Cancer Res (1999) 59(16):4129-35.

79. Pusenjak J, Miklavcic D. Interstitial fluid pressue as an obstacle in treatment of solid tumors. Radiol Oncol (1997) 31:291-7.

80. Swabb EA, Wei J, Gullino PM. Diffusion and convection in normal and neoplastic tissues. Cancer Res (1974) 34(10):2814-22.

81. Netti P, Jain RK. Interstitial transport in solid tumours. Cancer Modelling and Simulation. Chapman\&Hall/CRC press (2003). p. 51-74.

82. Welter $M$, Rieger $H$. Interstitial fluid flow and drug delivery in vascularized tumors: a computational model. PLoS One (2013) 8(8):e70395. doi:10.1371/ journal.pone.0070395

83. Soltani M, Chen P. Numerical modeling of fluid flow in solid tumors. PLoS One (2011) 6(6):e20344. doi:10.1371/journal.pone.0020344

84. Soltani M, Chen P. Numerical modeling of interstitial fluid flow coupled with blood flow through a remodeled solid tumor microvascular network. PLoS One (2013) 8(6):e67025. doi:10.1371/journal.pone.0067025

85. Stapleton S, Milosevic M, Allen C, Zheng J, Dunne M, Yeung I, et al. A mathematical model of the enhanced permeability and retention effect for liposome transport in solid tumors. PLoS One (2013) 8(12):e81157. doi:10.1371/ journal.pone. 0081157

86. Wiig H, Reed RK, Aukland K. Measurement of interstitial fluid pressure: comparison of methods. Ann Biomed Eng (1986) 14(2):139-51. doi:10.1007/ BF02584264

87. Wiig H. Evaluation of methodologies for measurement of interstitial fluid pressure (Pi): physiological implications of recent Pi data. Crit Rev Biomed Eng (1990) 18(1):27-54. 
88. HargensAR,CologneJB,MenningerFJ,HoganJS, TuckerBJ,PetersRM.Normal transcapillary pressures in human skeletal muscle and subcutaneous tissues. Microvasc Res (1981) 22(2):177-89. doi:10.1016/0026-2862(81)90087-X

89. Scholander PF, Hargens AR, Miller SL. Negative pressure in the interstitial fluid of animals. Fluid tensions are spectacular in plants; in animals they are elusively small, but just as vital. Science (1968) 161(3839):321-8. doi:10.1126/ science.161.3839.321

90. Fadnes HO, Reed RK, Aukland K. Interstitial fluid pressure in rats measured with a modified wick technique. Microvasc Res (1977) 14(1):27-36. doi:10.1016/0026-2862(77)90138-8

91. Wiederhielm CA, Weston BV. Microvascular, lymphatic, and tissue pressures in the unanesthetized mammal. Am J Physiol (1973) 225(4):992-6.

92. Wiig H, Reed RK, Aukland K. Micropuncture measurement of interstitial fluid pressure in rat subcutis and skeletal muscle: comparison to wick-inneedle technique. Microvasc Res (1981) 21(3):308-19. doi:10.1016/00262862(81)90014-5

93. Wiig H. Comparison of methods for measurement of interstitial fluid pressure in cat skin/subcutis and muscle. Am J Physiol (1985) 249(5 Pt 2):H929-44.

94. Tatsuo T, Toshiyo T, Oberg P. Pressure measurement. Biomedical Transducers and Instruments. CRC press (1997). p. 13-70.

95. Curti BD, Urba WJ, Alvord WG, Janik JE, Smith JW II, Madara K, et al. Interstitial pressure of subcutaneous nodules in melanoma and lymphoma patients:changes during treatment. Cancer Res (1993) 53(10 Suppl):2204-7.

96. Lyng H, Tufto I, Skretting A, Rofstad EK. Proton relaxation times and interstitial fluid pressure in human melanoma xenografts. Br J Cancer (1997) 75(2):180-3. doi:10.1038/bjc.1997.30

97. Hassid Y, Furman-Haran E, Margalit R, Eilam R, Degani H. Noninvasive magnetic resonance imaging of transport and interstitial fluid pressure in ectopic human lung tumors. Cancer Res (2006) 66(8):4159-66. doi:10.1158/00085472.CAN-05-3289

98. Hassid Y, Eyal E, Margalit R, Furman-Haran E, Degani H. Non-invasive imaging of barriers to drug delivery in tumors. Microvasc Res (2008) 76(2):94-103. doi:10.1016/j.mvr.2008.06.002

99. Gade TP, Buchanan IM, Motley MW, Mazaheri Y, Spees WM, Koutcher JA. Imaging intratumoral convection: pressure-dependent enhancement in chemotherapeutic delivery to solid tumors. Clin Cancer Res (2009) 15(1):247-55. doi:10.1158/1078-0432.CCR-08-0611

100. van der Veldt AA, Smit EF, Lammertsma AA. Positron emission tomography as a method for measuring drug delivery to tumors in vivo: the example of [(11)C]docetaxel. Front Oncol (2013) 3:208. doi:10.3389/fonc.2013.00208

101. Heldin CH, Rubin K, Pietras K, Ostman A. High interstitial fluid pressure - an obstacle in cancer therapy. Nat Rev Cancer (2004) 4(10):806-13. doi:10.1038/ nrc1456

102. Jain RK. Physiological barriers to delivery of monoclonal antibodies and other macromolecules in tumors. Cancer Res (1990) 50(3 Suppl):814s-9s.

103. Christiansen J, Rajasekaran AK. Biological impediments to monoclonal antibody-based cancer immunotherapy. Mol Cancer Ther (2004) 3(11):1493-501.

104. Chauhan VP, Stylianopoulos T, Boucher Y, Jain RK. Delivery of molecular and nanoscale medicine to tumors: transport barriers and strategies. Annu Rev Chem Biomol Eng (2011) 2:281-98. doi:10.1146/annurev-chembioeng061010-114300

105. Campbell RB. Tumor physiology and delivery of nanopharmaceuticals. Anticancer Agents Med Chem (2006) 6(6):503-12. doi:10.2174/187152006778 699077

106. Jain M, Venkatraman G, Batra SK. Optimization of radioimmunotherapy of solid tumors: biological impediments and their modulation. Clin Cancer Res (2007) 13(5):1374-82. doi:10.1158/1078-0432.CCR-06-2436

107. Stylianopoulos T, Martin JD, Snuderl M, Mpekris F, Jain SR, Jain RK. Coevolution of solid stress and interstitial fluid pressure in tumors during progression: implications for vascular collapse. Cancer Res (2013) 73(13):3833-41. doi:10.1158/0008-5472

108. Salnikov AV, Iversen VV, Koisti M, Sundberg C, Johansson L, Stuhr LB, et al. Lowering of tumor interstitial fluid pressure specifically augments efficacy of chemotherapy. FASEB J (2003) 17(12):1756-8.

109. Leunig M, Goetz AE, Gamarra F, Zetterer G, Messmer K, Jain RK. Photodynamic therapy-induced alterations in interstitial fluid pressure, volume and water content of an amelanotic melanoma in the hamster. $\mathrm{Br} J$ Cancer (1994) 69(1):101-3. doi:10.1038/bjc.1994.15
110. Chauhan VP, Martin JD, Liu H, Lacorre DA, Jain SR, Kozin SV, et al. Angiotensin inhibition enhances drug delivery and potentiates chemotherapy by decompressing tumour blood vessels. Nat Commun (2013) 4:2516. doi:10.1038/ncomms3516

111. Jain RK. Normalization of tumor vasculature: an emerging concept in antiangiogenic therapy. Science (2005) 307(5706):58-62. doi:10.1126/ science.1104819

112. Chauhan VP, Stylianopoulos T, Martin JD, Popović Z, Chen O, Kamoun WS, et al. Normalization of tumour blood vessels improves the delivery of nanomedicines in a size-dependent manner. Nat Nanotechnol (2012) 7(6):383-8. doi:10.1038/nnano.2012.45

113. Huang Y, Stylianopoulos T, Duda DG, Fukumura D, Jain RK. Benefits of vascular normalization are dose and time dependent - letter. Cancer Res (2013) 73(23):7144-6. doi:10.1158/0008-5472

114. Arjaans M, Oude Munnink TH, Oosting SF, Terwisscha van Scheltinga AG, Gietema JA, Garbacik ET, et al. Bevacizumab-induced normalization of blood vessels in tumors hampers antibody uptake. Cancer Res (2013) 73(11):3347-55. doi:10.1158/0008-5472.CAN-12-3518

115. Huang Y, Goel S, Duda DG, Fukumura D, Jain RK. Vascular normalization as an emerging strategy to enhance cancer immunotherapy. Cancer Res (2013) 73(10):2943-8. doi:10.1158/0008-5472.CAN-12-4354

116. Balamurugan K. HIF-1 at the crossroads of hypoxia, inflammation, and cancer. Int J Cancer (2015). doi:10.1002/ijc.29519

117. Shrimali RK, Yu Z, Theoret MR, Chinnasamy D, Restifo NP, Rosenberg SA. Antiangiogenic agents can increase lymphocyte infiltration into tumor and enhance the effectiveness of adoptive immunotherapy of cancer. Cancer Res (2010) 70(15):6171-80. doi:10.1158/0008-5472.CAN-10-0153

118. Heist RS, Duda DG, Sahani DV, Ancukiewicz M, Fidias P, Sequist LV, et al. Improved tumor vascularization after anti-VEGF therapy with carboplatin and nab-paclitaxel associates with survival in lung cancer. Proc Natl Acad Sci U S A (2015) 112(5):1547-52. doi:10.1073/pnas.1424024112

119. Gaya AM, Rustin GJ. Vascular disrupting agents: a new class of drug in cancer therapy. Clin Oncol (R Coll Radiol) (2005) 17(4):277-90. doi:10.1016/j. clon.2004.11.011

120. Skliarenko JV, Lunt SJ, Gordon ML, Vitkin A, Milosevic M, Hill RP. Effects of the vascular disrupting agent ZD6126 on interstitial fluid pressure and cell survival in tumors. Cancer Res (2006) 66(4):2074-80. doi:10.1158/00085472.CAN-05-2046

121. Ley CD, Horsman MR, Kristjansen PE. Early effects of combretastatin-A4 disodium phosphate on tumor perfusion and interstitial fluid pressure. Neoplasia (2007) 9(2):108-12.

122. Zlotecki RA, Baxter LT, Boucher Y, Jain RK. Pharmacologic modification of tumor blood flow and interstitial fluid pressure in a human tumor xenograft:network analysis and mechanistic interpretation. Microvasc Res (1995) 50(3):429-43. doi:10.1006/mvre.1995.1069

123. Vaupel P. Oxygenation of solid tumors. In: Teicher BA, editor. Drug Resistance in Oncology. New York, NY: Marcel Dekker Inc (1993). p. 53-85.

124. Podobnik B, Sersa G, Miklavcic D. Effect of hydralazine on interstitial fluid pressure in experimental tumours and in normal tissue. In Vivo (2001) 15(5):417-24.

125. Jarm T, Podobnik B, Sersa G, Miklavcic D. Effect of hydralazine on blood flow, oxygenation, and interstitial fluid pressure in subcutaneous tumors. $A d v$ Exp Med Biol (2003) 10:25-9. doi:10.1007/978-1-4615-0205-0_5

126. Brønstad A, Berg A, Reed RK. Effects of the taxanes paclitaxel and docetaxel on edema formation and interstitial fluid pressure. Am J Physiol Heart Circ Physiol (2004) 287(2):H963-8. doi:10.1152/ajpheart.01052.2003

127. Griffon-Etienne G, Boucher Y, Brekken C, Suit HD, Jain RK. Taxane-induced apoptosis decompresses blood vessels and lowers interstitial fluid pressure in solid tumors: clinical implications. Cancer Res (1999) 59(15):3776-82.

128. Taghian AG, Abi-Raad R, Assaad SI, Casty A, Ancukiewicz M, Yeh E, et al. Paclitaxel decreases the interstitial fluid pressure and improves oxygenation in breast cancers in patients treated with neoadjuvant chemotherapy: clinical implications. JClin Oncol (2005) 23(9):1951-61. doi:10.1200/JCO.2005.08.119

129. Aapro MS, Alberts DS. High-dose dexamethasone for prevention of cis-platin-induced vomiting. Cancer Chemother Pharmacol (1981) 7(1):11-4. doi:10.1007/BF00258206

130. Wang H, Li M, Rinehart JJ, Zhang R. Pretreatment with dexamethasone increases antitumor activity of carboplatin and gemcitabine in mice bearing 
human cancer xenografts: in vivo activity, pharmacokinetics, and clinical implications for cancer chemotherapy. Clin Cancer Res (2004) 10(5):1633-44. doi:10.1158/1078-0432.CCR-0829-3

131. Kristjansen PE, Boucher Y, Jain RK. Dexamethasone reduces the interstitial fluid pressure in a human colon adenocarcinoma xenograft. Cancer Res (1993) 53(20):4764-6.

132. Hahn GM. Hyperthermia for the engineer: a short biological primer. IEEE Trans Biomed Eng (1984) 31(1):3-8. doi:10.1109/TBME.1984.325363

133. Leunig M, Goetz AE, Dellian M, Zetterer G, Gamarra F, Jain RK, et al. Interstitial fluid pressure in solid tumors following hyperthermia: possible correlation with therapeutic response. Cancer Res (1992) 52(2):487-90.

134. Sen A, Capitano ML, Spernyak JA, Schueckler JT, Thomas S, Singh AK, et al. Mild elevation of body temperature reduces tumor interstitial fluid pressure and hypoxia and enhances efficacy of radiotherapy in murine tumor models. Cancer Res (2011) 71(11):3872-80. doi:10.1158/0008-5472.CAN$10-4482$

135. Rofstad EK, Gaustad JV, Brurberg KG, Mathiesen B, Galappathi K, Simonsen TG. Radiocurability is associated with interstitial fluid pressure in human tumor xenografts. Neoplasia (2009) 11(11):1243-51. doi:10.1593/neo.91152

136. Znati CA, Rosenstein M, Boucher Y, Epperly MW, Bloomer WD, Jain RK. Effect of radiation on interstitial fluid pressure and oxygenation in a human tumorxenograft. Cancer Res (1996) 56(5):964-8.

137. Agostinis P, Berg K, Cengel KA, Foster TH, Girotti AW, Gollnick SO, et al. Photodynamic therapy of cancer: an update. CA Cancer J Clin (2011) 61(4):250-81. doi:10.3322/caac.20114

138. Castano AP, Mroz P, Hamblin MR. Photodynamic therapy and anti-tumour immunity. Nat Rev Cancer (2006) 6(7):535-45. doi:10.1038/nrc1894

139. Perentes JY, Wang Y, Wang X, Abdelnour E, Gonzalez M, Decosterd L, et al. Low-dose vascular photodynamic therapy decreases tumor interstitial fluid pressure, which promotes liposomal doxorubicin distribution in a murine sarcoma metastasis model. Transl Oncol (2014) 7(3):393-9. doi:10.1016/j.tranon. 2014.04.010

140. Zhou Y. Ultrasound-mediated drug/gene delivery in solid tumor treatment. J Healthc Eng (2013) 4(2):223-54. doi:10.1260/2040-2295.4.2.223

141. Watson KD, Lai CY, Qin S, Kruse DE, Lin YC, Seo JW, et al. Ultrasound increases nanoparticle delivery by reducing intratumoral pressure and increasing transport in epithelial and epithelial-mesenchymal transition tumors. Cancer Res (2012) 72(6):1485-93. doi:10.1158/0008-5472.CAN11-3232

142. Nurwidya F, Takahashi F, Murakami A, Takahashi K. Epithelial mesenchymal transition in drug resistance and metastasis of lung cancer. Cancer Res Treat (2012) 44(3):151-6. doi:10.4143/crt.2012.44.3.151

143. Kalluri R, Weinberg RA. The basics of epithelial-mesenchymal transition. J Clin Invest (2009) 119(6):1420-8. doi:10.1172/JCI39104

144. Diop-Frimpong B, Chauhan VP, Krane S, Boucher Y, Jain RK. Losartan inhibits collagen I synthesis and improves the distribution and efficacy of nanotherapeutics in tumors. Proc Natl Acad Sci U S A (2011) 108(7):2909-14. doi:10.1073/pnas.1018892108

145. Netti PA, Berk DA, Swartz MA, Grodzinsky AJ, Jain RK. Role of extracellular matrix assembly in interstitial transport in solid tumors. Cancer Res (2000) 60(9):2497-503.

146. Lu P, Weaver VM, Werb Z. The extracellular matrix: a dynamic niche in cancer progression. J Cell Biol (2012) 196(4):395-406. doi:10.1083/jcb.201102147

147. Öhlund D, Elyada E, Tuveson D. Fibroblast heterogeneity in the cancer wound. J Exp Med (2014) 211(8):1503-23. doi:10.1084/jem.20140692

148. Schaefer L, Iozzo RV. Biological functions of the small leucine-rich proteoglycans: from genetics to signal transduction. J Biol Chem (2008) 283(31):21305-9. doi:10.1074/jbc.R800020200

149. Bonnans C, Chou J, Werb Z. Remodelling the extracellular matrix in development and disease. Nat Rev Mol Cell Biol (2014) 15(12):786-801. doi:10.1038/ nrm3904

150. Kim SH, Turnbull J, Guimond S. Extracellular matrix and cell signalling: the dynamic cooperation of integrin, proteoglycan and growth factor receptor. J Endocrinol (2011) 209(2):139-51. doi:10.1530/JOE-10-0377

151. Eikenes L, Bruland ØS, Brekken C, Davies Cde L. Collagenase increases the transcapillary pressure gradient and improves the uptake and distribution of monoclonal antibodies in human osteosarcoma xenografts. Cancer Res (2004) 64(14):4768-73. doi:10.1158/0008-5472.CAN-03-1472
152. Eikenes L, Tari M, Tufto I, Bruland OS, de Lange Davies C. Hyaluronidase induces a transcapillary pressure gradient and improves the distribution and uptake of liposomal doxorubicin (Caelyx) in human osteosarcoma xenografts. Br J Cancer (2005) 93(1):81-8. doi:10.1038/sj.bjc.6602626

153. Papageorgis $\mathrm{P}$, Stylianopoulos $\mathrm{T}$. Role of TGF $\beta$ in regulation of the tumor microenvironment and drug delivery (review). Int J Oncol (2015) 46(3):93343. doi:10.3892/ijo.2015.2816

154. Pietras K, Rubin K, Sjöblom T, Buchdunger E, Sjöquist M, Heldin CH, et al. Inhibition of PDGF receptor signaling in tumor stroma enhances antitumor effect of chemotherapy. Cancer Res (2002) 62(19):5476-84.

155. Baranowska-Kortylewicz J, Abe M, Pietras K, Kortylewicz ZP, Kurizaki T, Nearman J, et al. Effect of platelet-derived growth factor receptor-beta inhibition with STI571 on radioimmunotherapy. Cancer Res (2005) 65(17):7824-31. doi:10.1158/0008-5472.CAN-04-3991

156. Brekken C, Bruland ØS, de Lange Davies C. Interstitial fluid pressure in human osteosarcoma xenografts: significance of implantation site and the response to intratumoral injection of hyaluronidase. Anticancer Res (2000) 20(5B):3503-12.

157. Heuchel R, Berg A, Tallquist M, Ahlén K, Reed RK, Rubin K, et al. Plateletderived growth factor beta receptor regulates interstitial fluid homeostasis through phosphatidylinositol-3' kinase signaling. Proc Natl Acad Sci U S A (1999) 96(20):11410-5. doi:10.1073/pnas.96.20.11410

158. Egeblad M, Rasch MG, Weaver VM. Dynamic interplay between the collagen scaffold and tumor evolution. Curr Opin Cell Biol (2010) 22(5):697-706. doi:10.1016/j.ceb.2010.08.015

159. Zhong Z, Carroll KD, Policarpio D, Osborn C, Gregory M, Bassi R, et al. Anti-transforming growth factor beta receptor II antibody has therapeutic efficacy against primary tumor growth and metastasis through multieffects on cancer, stroma, and immune cells. Clin Cancer Res (2010) 16(4):1191-205. doi:10.1158/1078-0432.CCR-09-1634

160. Loeffler M, Krüger JA, Niethammer AG, Reisfeld RA. Targeting tumor-associated fibroblasts improves cancer chemotherapy by increasing intratumoral drug uptake. J Clin Invest (2006) 116(7):1955-62. doi:10.1172/JCI26532

161. Bouzin C, Feron O. Targeting tumor stroma and exploiting mature tumor vasculature to improve anti-cancer drug delivery. Drug Resist Updat (2007) 10(3):109-20. doi:10.1016/j.drup.2007.03.001

162. Deng PB, Hu CP, Xiong Z, Yang HP, Li YY. Treatment with EGCG in NSCLC leads to decreasing interstitial fluid pressure and hypoxia to improve chemotherapy efficacy through rebalance of Ang-1 and Ang-2. Chin J Nat Med (2013) 11(3):245-53. doi:10.1016/S1875-5364(13)60023-0

163. Kornfeld S, Goupille C, Vibet S, Chevalier S, Pinet A, Lebeau J, et al. Reducing endothelial NOS activation and interstitial fluid pressure with n-3 PUFA offset tumor chemoresistance. Carcinogenesis (2012) 33(2):260-7. doi:10.1093/ carcin/bgr274

164. Shim WS, Ho IA, Wong PE. Angiopoietin: a TIE(d) balance in tumor angiogenesis. Mol Cancer Res (2007) 5(7):655-65. doi:10.1158/1541-7786. MCR-07-0072

165. Merendino N, Costantini L, Manzi L, Molinari R, D’Eliseo D, Velotti F. Dietary $\omega-3$ polyunsaturated fatty acid DHA: a potential adjuvant in the treatment of cancer. Biomed Res Int (2013) 2013:310186. doi:10.1155/2013/310186

166. Au JL, Jang SH, Wientjes MG. Clinical aspects of drug delivery to tumors. J Control Release (2002) 78(1-3):81-95. doi:10.1016/S0168-3659(01)00488-6

167. Au JL, Jang SH, Zheng J, Chen CT, Song S, Hu L, et al. Determinants of drug delivery and transport to solid tumors. J Control Release (2001) 74(1-3):31-46. doi:10.1016/S0168-3659(01)00308-X

168. Trédan O, Galmarini CM, Patel K, Tannock IF. Drug resistance and the solid tumor microenvironment. J Natl Cancer Inst (2007) 99(19):1441-54. doi:10.1093/jnci/djm135

169. Solyanik GI. Multifactorial nature of tumor drug resistance. Exp Oncol (2010) 32(3):181-5.

170. Saggar JK, Yu M, Tan Q, Tannock IF. The tumor microenvironment and strategies to improve drug distribution. Front Oncol (2013) 3:154. doi:10.3389/ fonc.2013.00154

171. Minchinton AI, Tannock IF. Drug penetration in solid tumours. Nat Rev Cancer (2006) 6(8):583-92. doi:10.1038/nrc1893

172. Grantab RH, Tannock IF. Penetration of anticancer drugs through tumour tissue as a function of cellular packing density and interstitial fluid pressure and its modification by bortezomib. BMC Cancer (2012) 12:214. doi:10.1186/1471-2407-12-214 
173. Croix BS, Rak JW, Kapitain S, Sheehan C, Graham CH, Kerbel RS. Reversal by hyaluronidase of adhesion-dependent multicellular drug resistance in mammary carcinoma cells. J Natl Cancer Inst (1996) 88(18):1285-96. doi:10.1093/ jnci/88.18.1285

174. Mehta AI, Choi BD, Ajay D, Raghavan R, Brady M, Friedman AH, et al. Convection enhanced delivery of macromolecules for brain tumors. Curr Drug Discov Technol (2012) 9(4):305-10. doi:10.2174/157016312803305951

175. Bobo RH, Laske DW, Akbasak A, Morrison PF, Dedrick RL, Oldfield EH. Convection-enhanced delivery of macromolecules in the brain. Proc Natl Acad Sci U S A (1994) 91(6):2076-80. doi:10.1073/pnas.91.6.2076

176. Debinski W, Tatter SB. Convection-enhanced delivery for the treatment of brain tumors. Expert Rev Neurother (2009) 9(10):1519-27. doi:10.1586/ ern.09.99

177. Saito R, Bringas JR, McKnight TR, Wendland MF, Mamot C, Drummond DC, et al. Distribution of liposomes into brain and rat brain tumor models by convection-enhanced delivery monitored with magnetic resonance imaging. Cancer Res (2004) 64(7):2572-9. doi:10.1158/0008-5472.CAN-03-3631

178. Vandergrift WA, Patel SJ, Nicholas JS, Varma AK. Convection-enhanced delivery of immunotoxins and radioisotopes for treatment of malignant gliomas. Neurosurg Focus (2006) 20(4):E13. doi:10.3171/foc.2006.20.4.8

179. Yun J, Rothrock RJ, Canoll P, Bruce JN. Convection-enhanced delivery for targeted delivery of antiglioma agents: the translational experience. J Drug Deliv (2013) 2013:107573. doi:10.1155/2013/107573

180. Kong G, Braun RD, Dewhirst MW. Hyperthermia enables tumor-specific nanoparticle delivery: effect of particle size. Cancer Res (2000) 60(16):4440-5.

181. Frenkel V. Ultrasound mediated delivery of drugs and genes to solid tumors. Adv Drug Deliv Rev (2008) 60(10):1193-208. doi:10.1016/j.addr.2008.03.007

182. Alitalo A, Detmar M. Interaction of tumor cells and lymphatic vessels in cancer progression. Oncogene (2012) 31(42):4499-508. doi:10.1038/onc.2011.602

183. Tammela T, Zarkada G, Wallgard E, Murtomäki A, Suchting S, Wirzenius M, et al. Blocking VEGFR-3 suppresses angiogenic sprouting and vascular network formation. Nature (2008) 454(7204):656-60. doi:10.1038/nature07083

184. Azzi S, Hebda JK, Gavard J. Vascular permeability and drug delivery in cancers. Front Oncol (2013) 3:211. doi:10.3389/fonc.2013.00211

185. García-Román J, Zentella-Dehesa A. Vascular permeability changes involved in tumor metastasis. Cancer Lett (2013) 335(2):259-69. doi:10.1016/j.canlet. 2013.03.005

186. Gavard J, Patel V, Gutkind JS. Angiopoietin-1 prevents VEGF-induced endothelial permeability by sequestering Src through mDia. Dev Cell (2008) 14(1):25-36. doi:10.1016/j.devcel.2007.10.019

187. Jain RK. Normalizing tumor microenvironment to treat cancer: bench to bedside to biomarkers. J Clin Oncol (2013) 31(17):2205-18. doi:10.1200/ JCO.2012.46.3653

188. Sorensen AG, Emblem KE, Polaskova P, Jennings D, Kim H, Ancukiewicz $M$, et al. Increased survival of glioblastoma patients who respond to antiangiogenic therapy with elevated blood perfusion. Cancer Res (2012) 72(2):402-7; Erratum in: Cancer Res (2012) 72(5):1316. Cancer Res (2012) 72(2). doi:10.1158/0008-5472.CAN-11-2464

189. Gerstner ER, Batchelor TT. Antiangiogenic therapy for glioblastoma. Cancer $J$ (2012) 18(1):45-50. doi:10.1097/PPO.0b013e3182431c6f

190. Pishko GL, Muldoon LL, Pagel MA, Schwartz DL, Neuwelt EA. Vascular endothelial growth factor blockade alters magnetic resonance imaging biomarkers of vascular function and decreases barrier permeability in a rat model of lung cancer brain metastasis. Fluids Barriers CNS (2015) 12:5. doi:10.1186/2045-8118-12-5

191. Li JL, Sainson RC, Shi W, Leek R, Harrington LS, Preusser M, et al. Delta-like 4 Notch ligand regulates tumor angiogenesis, improves tumor vascular function, and promotes tumor growth in vivo. Cancer Res (2007) 67(23):11244-53. doi:10.1158/0008-5472.CAN-07-0969

192. Casey SC, Amedei A, Aquilano K, Azmi AS, Benencia F, Bhakta D, et al. Cancer prevention and therapy through the modulation of the tumor microenvironment. Semin Cancer Biol (2015). doi:10.1016/j.semcancer.2015. 02.007

193. Abès R, Teillaud JL. Modulation of tumor immunity by therapeutic monoclonal antibodies. Cancer Metastasis Rev (2011) 30(1):111-24. doi:10.1007/ s10555-011-9282-3

194. Leibovici J, Itzhaki O, Huszar M, Sinai J. The tumor microenvironment: part 1. Immunotherapy (2011) 3(11):1367-84. doi:10.2217/imt.11.111
195. Gillies RJ, Raghunand N, Karczmar GS, Bhujwalla ZM. MRI of the tumor microenvironment. J Magn Reson Imaging (2002) 16(4):430-50; Erratum in: J Magn Reson Imaging (2002) 16(6):751. doi:10.1002/jmri.10181

196. Penet MF, Krishnamachary B, Chen Z, Jin J, Bhujwalla ZM. Molecular imaging of the tumor microenvironment for precision medicine and theranostics. $A d v$ Cancer Res (2014) 124:235-56. doi:10.1016/B978-0-12-411638-2.00007-0

197. Khawar IA, Kim JH, Kuh HJ. Improving drug delivery to solid tumors: priming the tumor microenvironment. J Control Release (2015) 201:78-89. doi:10.1016/j.jconrel.2014.12.018

198. Narunsky L, Oren R, Bochner F, Neeman M. Imaging aspects of the tumor stroma with therapeutic implications. Pharmacol Ther (2014) 141(2):192208. doi:10.1016/j.pharmthera.2013.10.003

199. Kuszyk BS, Corl FM, Franano FN, Bluemke DA, Hofmann LV, Fortman $\mathrm{BJ}$, et al. Tumor transport physiology: implications for imaging and imaging-guided therapy. AJR Am J Roentgenol (2001) 177(4):747-53. doi:10.2214/ ajr.177.4.1770747

200. Kim M, Gillies RJ, Rejniak KA. Current advances in mathematical modeling of anti-cancer drug penetration into tumor tissues. Front Oncol (2013) 3:278. doi:10.3389/fonc.2013.00278

201. Albini A, Pennesi G, Donatelli F, Cammarota R, De Flora S, Noonan DM. Cardiotoxicity of anticancer drugs: the need for cardio-oncology and cardio-oncological prevention. J Natl Cancer Inst (2010) 102(1):14-25. doi:10.1093/jnci/djp440

202. Burlá AK, Lobato NS, Fortes ZB, Oigman W, Neves MF. Cardiac fibrosis and vascular remodeling are attenuated by metformin in obese rats. Int $J$ Cardiol (2013) 165(3):483-7. doi:10.1016/j.ijcard.2011.09.012

203. Orecchioni S, Reggiani F, Talarico G, Mancuso P, Calleri A, Gregato G, et al. The biguanides metformin and phenformin inhibit angiogenesis, local and metastatic growth of breast cancer by targeting both neoplastic and microenvironment cells. Int J Cancer (2015) 136(6):E534-44. doi:10.1002/ijc.29193

204. Baronzio G, Freitas I, Kwaan HC. Tumor microenvironment and hemorheological abnormalities. Semin Thromb Hemost (2003) 29(5):489-97. doi:10.1055/s-2003-44557

205. Leguerney I, Lassau N, Koscielny S, Rodrigues M, Massard C, Rouffiac V, et al. Combining functional imaging and interstitial pressure measurements to evaluate two anti-angiogenic treatments. Invest New Drugs (2012) 30(1):144-56. doi:10.1007/s10637-010-9543-y

206. Maeda H. Toward a full understanding of the EPR effect in primary and metastatic tumors as well as issues related to its heterogeneity. Adv Drug Deliv Rev (2015). doi:10.1016/j.addr.2015.01.002

207. Jang SH, Wientjes MG, Lu D, Au JL. Drug delivery and transport to solid tumors. Pharm Res (2003) 20(9):1337-50. doi:10.1023/A:1025785505977

208. Ribatti D. Vascular normalization: a real benefit? Cancer Chemother Pharmacol (2011) 68(2):275-8. doi:10.1007/s00280-011-1683-z

209. Datta NR, Ordóñez SG, Gaipl US, Paulides MM, Crezee H, Gellermann J, et al. Local hyperthermia combined with radiotherapy and-/or chemotherapy: Recent advances and promises for the future. Cancer Treat Rev (2015). doi:10.1016/j.ctrv.2015.05.009

210. Hurwitz M, Stauffer P. Hyperthermia, radiation and chemotherapy: the role of heat in multidisciplinary cancer care. Semin Oncol (2014) 41(6):714-29. doi:10.1053/j.seminoncol.2014.09.014

211. Wiig H, Keskin D, Kalluri R. Interaction between the extracellular matrix and lymphatics: consequences for lymphangiogenesis and lymphatic function. Matrix Biol (2010) 29(8):645-56. doi:10.1016/j.matbio.2010.08.001

212. Rejniak KA, Estrella V, Chen T, Cohen AS, Lloyd MC, Morse DL. The role of tumor tissue architecture in treatment penetration and efficacy: an integrative study. Front Oncol (2013) 3:111. doi:10.3389/fonc.2013.00111

Conflict of Interest Statement: The authors declare that the research was conducted in the absence of any commercial or financial relationships that could be construed as a potential conflict of interest.

Copyright (๑ 2015 Baronzio, Parmar and Baronzio. This is an open-access article distributed under the terms of the Creative Commons Attribution License (CC BY). The use, distribution or reproduction in other forums is permitted, provided the original author(s) or licensor are credited and that the original publication in this journal is cited, in accordance with accepted academic practice. No use, distribution or reproduction is permitted which does not comply with these terms. 